\title{
Charge Transfer Fluorescence and 34 nm Exciton Diffusion Length in Polymers with Electron Acceptor End Traps
}

Lori Zaikowski ${ }^{1,2 *}$, Gina Mauro ${ }^{1,2}$, Matthew Bird, ${ }^{2}$ Brianne Karten ${ }^{1}$, Sadayuki Asaoka ${ }^{4, \dagger}$, Qin $\mathrm{Wu}^{3}$, Andrew R. Cook, ${ }^{2}$ and John R. Miller ${ }^{2 *}$

${ }^{1}$ Chemistry and Physics Department, Dowling College, Oakdale, NY

${ }^{2}$ Chemistry Department, Brookhaven National Laboratory, Upton, NY

${ }^{3}$ Center for Functional Nanomaterials, Brookhaven National Laboratory, Upton, NY

${ }^{4}$ Department of Biomolecular Engineering, Kyoto Institute of Technology, Matsugasaki, Sakyo-ku, Kyoto 6068585, Japan

*Correspondence: zaikowskium@gmail.com

\begin{abstract}
Photoexcitation of conjugated poly-2,7-(9,9-dihexylfluorene) polyfluorenes with naphthylimide (NI) and anthraquinone (AQ) electron-acceptor end traps produces excitons that form charge transfer states at the end traps. Intramolecular singlet exciton transport to end traps was examined by steady state fluorescence for polyfluorenes of 17 to 127 repeat units in chloroform, dimethylformamide (DMF), tetrahydrofuran (THF), and p-xylene. End traps capture excitons and form charge transfer (CT) states at all polymer lengths and in all solvents. The CT nature of the end-trapped states is confirmed by their fluorescence spectra, solvent and trap group dependence and DFT descriptions. Quantum yields of CT fluorescence are as large as $46 \%$. This strong CT emission is understood in terms of intensity borrowing. Energies of the CT states from onsets of the fluorescence spectra give the depths of the traps which vary with solvent polarity. For NI end traps the trap depths are 0.06 (p-xylene), 0.13 (THF) and $0.19 \mathrm{eV}$ $\left(\mathrm{CHCl}_{3}\right)$. For AQ, CT fluorescence could be observed only in p-xylene where the trap depth is $0.27 \mathrm{eV}$. Quantum yields, emission energies, charge transfer energies, solvent reorganization and vibrational energies were calculated. Fluorescence measurements on chains $>100$ repeat units indicate that end traps capture $\sim 50 \%$ of the excitons, and that the exciton diffusion length $\mathrm{L}_{\mathrm{D}}=34$ $\mathrm{nm}$, which is much larger than diffusion lengths reported in polymer films or than previously
\end{abstract}


known for diffusion along isolated chains. The efficiency of exciton capture depends on chain length, but not on trap depth, solvent polarity or which trap group is present.

KEYWORDS: Exciton trapping, Charge transfer state, conjugated polymer, polyfluorene, exciton diffusion, diffusion length, charge transfer exciton

\section{Introduction}

A principal problem in organic solar cells is transport of excitons to junctions where they can split to form electrons and holes. The advent of bulk heterojunction (BHJ) cells addressed this problem by creation of nano-domains of donor and acceptor material so only short exciton diffusion lengths are necessary. ${ }^{1-34}$ The BHJ concept is now almost universal, although it does lead to other problems, especially in transport of electrons and holes, which limit efficiency of organic photovoltaics (OPV). It is therefore reasonable to ask: Can there be alternatives to living with short exciton diffusion lengths? The properties of conjugated chains suggest the possibility of efficient transport over long distances; at least along single continuous chains. That possibility was questioned by experiments with polyindenofluorene chains having perylenedimide caps ${ }^{5,6}$ that found transport to be inherently slow. On the other hand, experiments in this laboratory suggested faster transport, ${ }^{7}$ but both results utilized relatively short chains. Healy ${ }^{8}$ examined steady state fluorescence quenching on polythiophene chains with fullerene end traps, finding a diffusion length $L_{D}=7 \mathrm{~nm}$, which is similar to exciton diffusion lengths reported in polymer films, ${ }^{9-14}$ which are in accord with theory. ${ }^{15}$

The present work examines charge transfer fluorescence and exciton movement in long polyfluorene $(\mathrm{pF})$ chains with naphthylimide (NI) and anthraquinone (AQ) acceptor trap groups at the ends (Chart 1, Figure 1). Below we report exciton transfer to trap groups at the ends of conjugated chains as a function of chain length, solvent, and end trap using steady state fluorescence. Theoretical calculations were performed using linear response time-dependent density functional theory (TDDFT) to gain insight into the nature of the charge transfer states and the emission solvent dependence. 

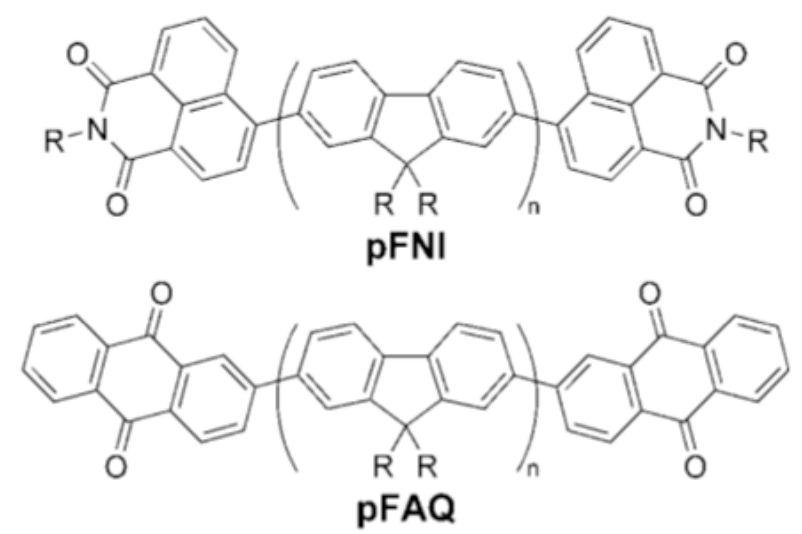

Chart 1. Polyfluorenes with naphthylimide $\left(\mathrm{pF}_{\mathrm{n}} \mathrm{NI}\right)$ and anthraquinone $\left(\mathrm{pF}_{\mathrm{n}} \mathrm{AQ}\right)$ end traps. $\mathrm{R}=$ $\mathrm{C}_{6} \mathrm{H}_{13} . \mathrm{n}=17-127$

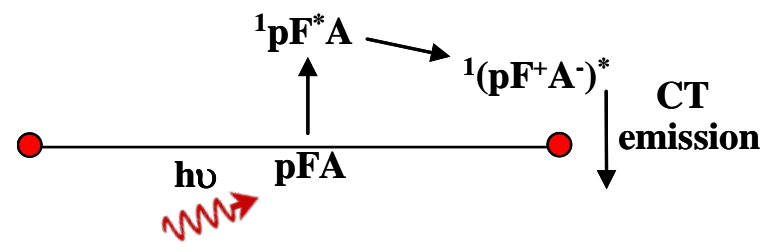

Figure 1. Photoexcitation produces excitons that form a charge transfer (CT) state when they reach end trap acceptors (A), and emit a photon when the CT exciton radiatively decays.

\section{Results}

Figure 2 and Tables 1-2 report measurements of fluorescence spectra and intensities after $380 \mathrm{~nm}$ photoexcitation of polyfluorenes without and with end traps. The $380 \mathrm{~nm}$ excitation light is absorbed almost exclusively by the strong bands of $\mathrm{pF}$ chains to form excitons in the chains. Results reported below measure resulting fluorescence and estimate the efficiency of exciton transport to the trap groups as a function of chain length and the behavior of the excitons at the traps. The 27 polymer fractions of different lengths and caps were measured initially in all four solvents, and selected polymers were subsequently re-measured multiple times to obtain reproducibility within 1-2\%. In DMF poor solubility and evidence of interchain and/or intrachain aggregation in both absorption and emission spectroscopy (Figures S1 and S2) includes smaller absorption and emission intensities, long wavelength tails in the absorption spectra and long wavelength contributions to the emission spectra. These made observations in DMF difficult to interpret, so little will be reported about the DMF results. The energy of the pF chain excitons in 
DMF, estimated as the energy of crossing of absorption and fluorescence spectra (Figure S3), is lower than in other solvents, while the energy of the CT state appears to be higher, approximately equaling the energy of the $\mathrm{pF}$ chain states. Fluorescence emission spectra of $\mathrm{pF}$ chains without trap groups in THF, chloroform and p-xylene showed small, but repeatable differences in intensity and energy shown in Table 1and Figure 2a. No differences were found for uncapped $\mathrm{pF}$ fractions of different lengths. Fluorescence spectra of pFNI and pFAQ (both abbreviated as $\mathrm{pFA}$ ) show emissions from both the $\mathrm{pF}$ chain, referred to as "chain fluorescence," and new emissions that will be identified as charge transfer (CT) states at the end traps (Figure 2b). $\mathrm{pF}$ chain intensities in $\mathrm{pFA}$ are less than uncapped $\mathrm{pF}$ intensities due to exciton transport and charge transfer to end traps $\left(\mathrm{pF}^{+} \mathrm{A}^{-}\right)$that results in charge transfer fluorescence. As pFA polymer length decreases, charge transfer fluorescence increases and $\mathrm{pF}$ chain fluorescence decreases. In the longest end capped polymers, $\mathrm{pF}_{117} \mathrm{NI}$ and $\mathrm{pF}_{127} \mathrm{AQ}$, evidence of exciton transport to end caps is observed, wherein $\mathrm{pF}$ chain fluorescence is half as intense as in uncapped pF. Emissions from the locally excited states of naphthylimide and anthraquinone ${ }^{16-18 ; 19-21}$ are not observed; only charge transfer state emissions occur at the end traps.

Table 1. Energy $(\mathrm{eV})$ of maximum fluorescence emission intensity $\left(\mathrm{E}_{\mathrm{max}}\right)$ and average energy of charge transfer band origins $\left(\mathrm{E}_{0}\right)$. $\mathrm{E}_{\max }(\mathrm{pF})-\mathrm{E}_{0}(\mathrm{pFA})$ gives trap depths for $\mathrm{pFNI}$ of 0.06 (xyl), 0.13 (THF) and $0.19\left(\mathrm{CHCl}_{3}\right)$ and $0.27 \mathrm{eV}$ for $\mathrm{pFAQ}$ in xylene. $\mathrm{E}_{0}$ for $\mathrm{pF}$ is the chain fluoresence origin.

\begin{tabular}{ccccccc} 
& & Xylene & THF & $\mathrm{CHCl}_{3}$ & $\mathrm{DMF}^{\mathrm{c}}$ & $\mathrm{E}_{\mathrm{CT}}\left(\mathrm{pFA}^{\mathrm{c}}\right)^{\mathrm{d}}$ \\
\hline $\mathrm{pF}^{\mathrm{a}}$ & $\mathrm{E}_{\max }$ & 3.00 & 2.98 & 2.99 & & \\
& & & & & 2.90 & \\
& $\mathrm{E}_{0}$ & 3.08 & 3.05 & 3.06 & 3.0 & \\
$\mathrm{pFNI}$ & $\mathrm{E}_{\max }$ & 2.76 & 2.34 & 2.28 & & 1.21 \\
& & & & & 2.4 & \\
& $\mathrm{E}_{0}$ & 2.94 & 2.85 & 2.80 & & 0.85 \\
$\mathrm{pFAQ}^{\mathrm{b}}$ & $\mathrm{E}_{\max }$ & 2.41 & n.o. & n.o. & & 1.7
\end{tabular}


$\mathrm{E}_{0} \quad 2.73 \quad$ n.o. $\quad$ n.o.

${ }^{\mathrm{a}} \mathrm{pF}_{45} \quad{ }^{\mathrm{b}}$ n.o. $=$ not observed. ${ }^{\mathrm{c}}$ Energies in DMF may be suspect and are more uncertain due to aggregration. ${ }^{\mathrm{d}}$ Energies of charge transfer (CT) bands for $\mathrm{PFNI}^{--}$and $\mathrm{pFAQ}{ }^{--}$anions reported by Asaoka $^{22}$ in THF.

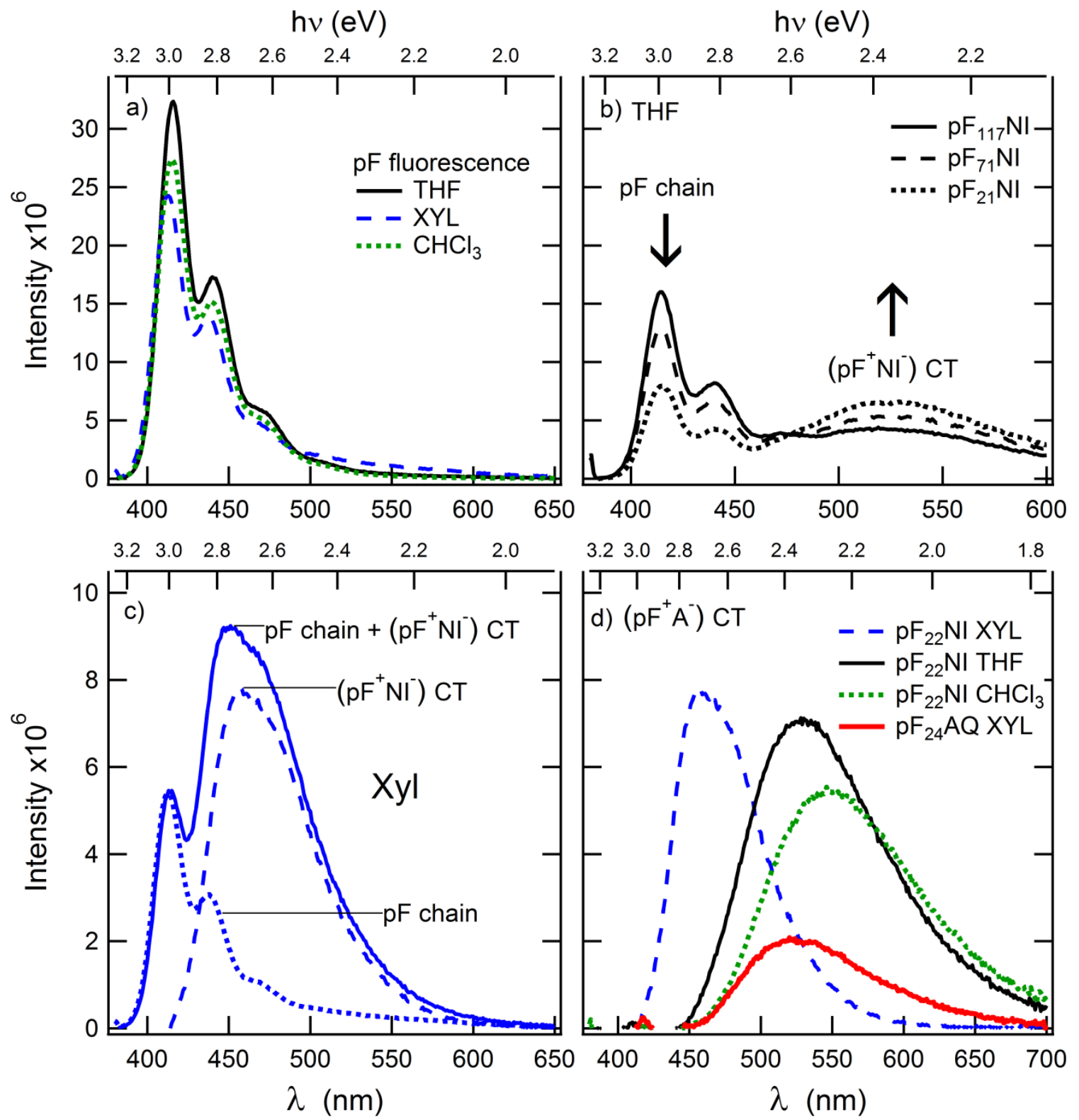

Figure 2. Steady state fluorescence emission spectra. (a) pF chain fluorescence of uncapped pF in THF (black solid), chloroform (green dotted), and xylene (blue dashed). Average pF peak intensity in THF $=32.3 \times 10^{6}$ counts/s, chloroform $=27.4 \times 10^{6}$ counts/s, xylene $=24.2 \times 10^{6}$ counts/s, DMF (not shown) $=0.75 \times 10^{6}$ counts/s. (b) pFNI emissions in THF. Note decrease in 
$\mathrm{pF}$ chain intensity compared to uncapped $\mathrm{pF}$ in Fig. 2a. (c) $\mathrm{pF}_{22} \mathrm{NI}$ emission in xylene (blue solid). pF chain contribution (blue dotted) subtracted to give solely ( $\mathrm{pF}^{+} \mathrm{NI}^{-}$) $\mathrm{CT}$ spectrum (blue dashed). (d) CT fluorescence with pF chain contribution subtracted. ( $\mathrm{pF}^{+} \mathrm{NI}^{-}$) in xylene (blue dashed), THF (black solid), chloroform (green dotted). ( $\left.\mathrm{pF}^{+} \mathrm{AQ}^{-}\right)$in xylene (thick red solid). ( $\left.\mathrm{pF}^{+} \mathrm{AQ}^{-}\right) \mathrm{CT}$ fluorescence is negligible in THF and chloroform.

Table 2. Quantum yields, charge-transfer state energies, and reorganization energies of pFNI and $\mathrm{pFAQ}^{\mathrm{a}}$. The fraction of $\mathrm{pF}$ chain fluorescence, is the ratio of peak chain fluorescence from $\mathrm{pFNI}$ or $\mathrm{pFAQ}$ to that in uncapped $\mathrm{pF},\left(\mathrm{F}_{\mathrm{c}}\right)=\mathrm{I}_{\mathrm{pFA}} / \mathrm{I}_{\mathrm{pF}}$. Also reported are the chain fluorescence quantum yield $\left(\phi_{c}\right)$ per photon absorbed, charge transfer state $\left(\mathrm{pF}^{+} \mathrm{A}^{-}\right)$quantum yield per photon absorbed $\left(\phi_{\mathrm{CT}} / \mathrm{hv}\right)$, charge transfer state quantum yield per trapped exciton $\left(\phi_{\mathrm{CT} / \mathrm{exT}}\right)$, charge transfer state energy $\left(\mathrm{E}_{0} \mathrm{CT}\right)$, solvent reorganization energy $\left(\lambda_{\mathrm{s}}\right)$, and vibrational reorganization energy $\left(\lambda_{\mathrm{v}}\right)$.

\begin{tabular}{cccccccccccc}
\hline & $\mathrm{pF}_{22} \mathrm{NI}$ & $\mathrm{pF}_{71} \mathrm{NI}$ & $\mathrm{pF}_{117} \mathrm{NI}$ & $\mathrm{pF}_{22} \mathrm{NI}$ & $\mathrm{pF}_{71} \mathrm{NI}$ & $\mathrm{pF}_{117} \mathrm{NI}$ & $\mathrm{pF}_{22} \mathrm{NI}^{2}$ & $\mathrm{pF}_{117} \mathrm{NI}^{2}$ & $\mathrm{pF}_{20} \mathrm{AQ}^{2}$ & $\mathrm{pF}_{81} \mathrm{AQ}$ & $\mathrm{pF}_{127} \mathrm{AQ}$ \\
& $\mathrm{XYL}$ & $\mathrm{XYL}$ & $\mathrm{XYL}$ & $\mathrm{THF}$ & $\mathrm{THF}$ & $\mathrm{THF}$ & $\mathrm{CHCl}_{3}$ & $\mathrm{CHCl}_{3}$ & $\mathrm{XYL}$ & $\mathrm{XYL}$ & $\mathrm{XYL}$ \\
\hline $\mathrm{F}_{\mathrm{c}}{ }^{\mathrm{a}}$ & 0.28 & 0.43 & 0.56 & 0.25 & 0.40 & 0.49 & 0.20 & 0.53 & 0.25 & 0.49 & 0.58 \\
$\phi_{\mathrm{c}}$ & 0.19 & 0.28 & 0.36 & 0.19 & 0.30 & 0.37 & 0.14 & 0.39 & 0.16 & 0.32 & 0.37 \\
$\phi_{\mathrm{CT}} / \mathrm{hv}^{\mathrm{a}}$ & 0.46 & 0.30 & 0.24 & 0.39 & 0.31 & 0.24 & 0.32 & 0.20 & 0.12 & 0.08 & 0.07 \\
$\phi_{\mathrm{CT}} / \mathrm{eXT}^{\mathrm{a}}$ & 0.64 & 0.52 & 0.55 & 0.52 & 0.51 & 0.48 & 0.40 & 0.42 & 0.16 & 0.16 & 0.16 \\
$\mathrm{E}_{0} \mathrm{CT}$ & 2.93 & 2.93 & 2.95 & 2.86 & 2.85 & 2.85 & 2.81 & 2.79 & 2.73 & 2.70 & 2.76 \\
$\lambda_{\mathrm{s}}$ & 0.18 & 0.17 & 0.20 & 0.42 & 0.42 & 0.42 & 0.44 & 0.41 & 0.25 & 0.21 & 0.28 \\
$\lambda_{\mathrm{v}}$ & 0.14 & 0.14 & 0.13 & 0.14 & 0.14 & 0.14 & 0.14 & 0.14 & 0.14 & 0.16 & 0.16
\end{tabular}

${ }^{\mathrm{a}}$ For short pFAQs in THF and $\mathrm{CHCl}_{3} \mathrm{~F}_{\mathrm{c}}=0.26, \phi_{\mathrm{CT}} / \mathrm{hv}$ is $<0.02$ and $\phi_{\mathrm{CT}} / \mathrm{exT}$ is $\leq 0.025$. $\mathrm{E}_{0} \mathrm{CT}$ could not be determined for pFAQs in THF and $\mathrm{CHCl}_{3}$ due to low signal to noise.

CT fluorescence is solvent dependent. In a given solvent the observed fluorescence spectra were well described as sums of two contributions: pF chain fluorescence and charge transfer (CT) fluorescence. CT fluorescence spectra were obtained in each solvent by subtracting the $\mathrm{pF}$ chain contribution from the overlapping $\mathrm{pF}$ chain and CT spectra (Figure 2c and 2d). For different chain lengths the shapes of the two spectra remained the same, only the relative intensities changed. The chain and CT fluorescence intensities are plotted against chain length in Figure 3, showing a decrease in pF chain emission intensity and increase in CT emission intensity as chain length decreases. CT emissions have the highest quantum yields and highest emission energies (are bluest) in xylene; pFNI CT emission energies shift red by $0.4 \mathrm{eV}$ in THF, and slightly further red in chloroform. pFAQ CT fluorescence is observed in xylene, but is 
minimal in polar solvents. Evidence of pFAQ charge transfer is seen in the marked decrease in $\mathrm{pF}$ chain fluorescence intensity compared to uncapped $\mathrm{pF}$ (Table 2). The reduced intensity of pFAQ CT fluorescence compared to pFNI is not indicative of less charge transfer, but of competing non-radiative decay pathways for the CT state. In DMF CT fluorescence is observed for pFNI (Figure S2) at almost the same energy as in THF and chloroform.

The high energy onsets of the CT fluorescence mark the energies (origins), $\mathrm{E}_{0, \mathrm{CT}}$, of the CT states relative to the ground states. These onsets may be estimated by inspection of the curves in Figure 2. Improved estimates fit the CT fluorescence spectra using an expression ${ }^{23}$ for the Franck-Condon envelope, using an onset energy, $\mathrm{E}_{0, \mathrm{CT}}$, and solvent and high-frequency reorganization energies reported in Table 2. Table 1 also compares the origins and maxima of the CT fluorescence bands with origins and maxima of CT absorption bands for anions of pFNI and pFAQ reported in $\mathrm{THF}^{22}$

Absolute quantum yields in selected short and long end-capped polyfluorenes for the $\mathrm{pF}$ chain $\left(\phi_{\mathrm{c}}\right)$ and CT fluorescence per photon absorbed $\left(\phi_{\mathrm{CT}} / \mathrm{hu}\right)$ and per trapped exciton $\left(\phi_{\mathrm{CT} / \mathrm{exT}}\right)$ are reported in Table 2. Quantum yields were determined by integrating fluorescence spectra of absorption-matched solutions, and correcting for refractive index differences between solvents. A reported value for $\mathrm{pF}$ chain quantum efficiency $(\phi=0.64)$ was used as a standard to which endcapped chains were compared. Charge transfer state $\left(\mathrm{pF}^{+} \mathrm{A}^{-}\right)$quantum yields per photon absorbed were calculated by Equation 1, where $\mathrm{F}_{\mathrm{CT}}=$ (area CT fluorescence spectrum in solvent)/(area uncapped $\mathrm{pF}$ fluorescence spectrum in solvent), and $\phi_{\mathrm{PF}}=$ (area uncapped $\mathrm{pF}$ spectrum in solvent $) /($ area uncapped pF spectrum in xylene $) *\left(\mathrm{n}_{\text {solvent }} / \mathrm{n}_{\text {xylene }}\right)^{2} * 0.64$.

$$
\left(\phi_{\mathrm{CT}} / \mathrm{hv}\right)=\left(\mathrm{F}_{\mathrm{CT}}\right)\left(\phi_{\mathrm{PF}}\right)
$$

Quantum yields of charge transfer state fluorescence per trapped exciton were calculated by Equation 2, where $F_{\text {exT }}=F_{C T} /\left(1-F_{c}\right)$, where $F_{c}$ is the fraction of chain fluorescence in pFA compared to $\mathrm{pF}$, and $\left(1-\mathrm{F}_{\mathrm{c}}\right)$ is the fraction of excitons that make it to an end trap.

$$
\left(\phi_{\mathrm{CT} / \mathrm{exT}}\right)=\left(\mathrm{F}_{\mathrm{exT}}\right)\left(\phi_{\mathrm{PF}}\right)
$$

Charge transfer fluorescence quantum yields per trapped exciton $\left(\phi_{\mathrm{CT} / \mathrm{exT}}\right)$ for a given solvent and end trap do not change much with polymer length, but are about $15 \%$ higher in xylene than in THF and 40\% higher in xylene than in chloroform and increase with increasing energy of the CT state (Figure S4). Regardless of the nature of the end trap or solvent, chain 
fluorescence quantum yields $\left(\phi_{c}\right)$ per photon absorbed are $1.9-2.8$ times larger in the longest pFA compared to the shortest, and charge transfer state $\left(\mathrm{pF}^{+} \mathrm{A}\right)$ quantum yields per photon absorbed ( $\phi_{\mathrm{CT}} / \mathrm{hv}$ ) are 1.6 to 1.9 times higher in short versus long polymers (Figure 4). However, charge transfer state $\left(\mathrm{pF}^{+} \mathrm{A}^{-}\right)$quantum yields per photon absorbed $\left(\phi_{\mathrm{CT}} / \mathrm{hv}\right)$ and per trapped exciton $\left(\phi_{\mathrm{CT} / \mathrm{exT}}\right)$ are about three times higher for pFNI than pFAQ.

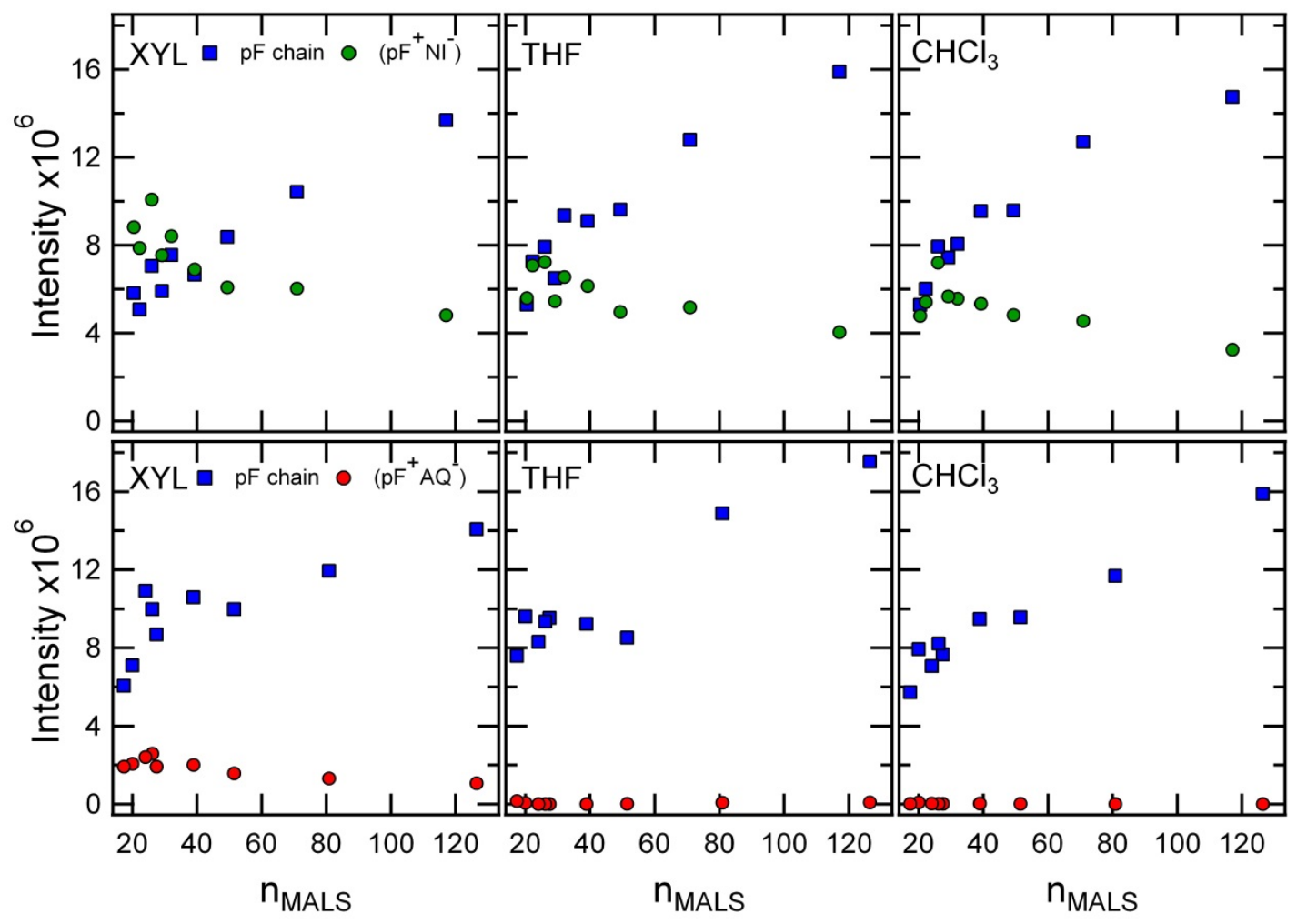

Figure 3. Separation of $\mathrm{pF}$ chain fluorescence from ${ }^{1} \mathrm{pF}^{*}$ and charge transfer $\left(\mathrm{pF}^{+} \mathrm{A}^{-}\right)$ fluorescence peak intensity plotted versus average polymer length for pFNI and $\mathrm{pFAQ}$ in xylene, THF, and chloroform. 


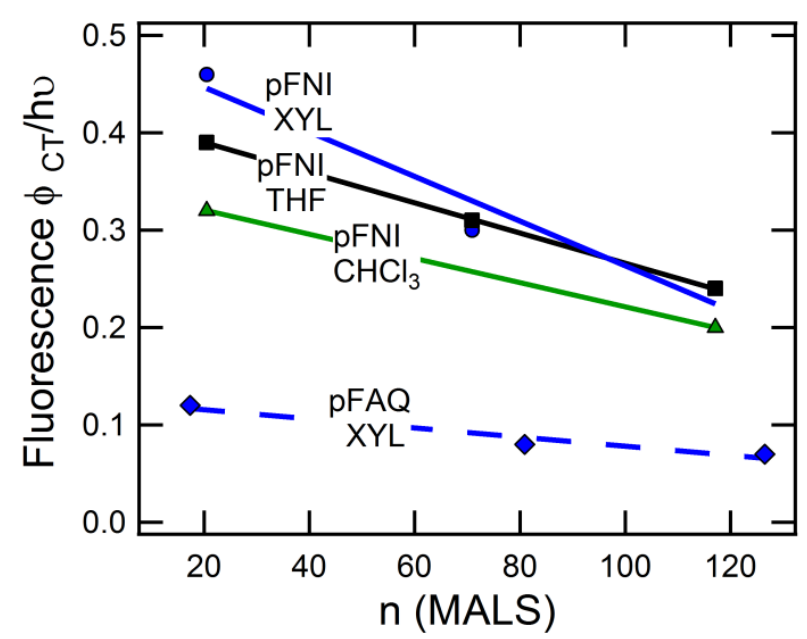

Figure 4. Charge transfer state $\left(\mathrm{pF}^{+} \mathrm{A}^{-}\right)$quantum yields per photon absorbed $\left(\phi_{\mathrm{CT}} / \mathrm{hv}\right)$ plotted as a function of polymer length. Uncertainties $1-2 \%$.

Density Functional Theory. To gain further insight into the spectra, we carried out calculations using linear response time-dependent density functional theory (TDDFT) ${ }^{26,25,27}$ in conjunction with a polarizable continuum model (PCM) for solvation ${ }^{28}$, as implemented in the Gaussian 09 software package ${ }^{29}$. Our model compounds are made up of a fluorene trimer with one end capped by an either NI or AQ group; no chain-length dependence was studied. Rather our goals are to provide some understanding of the fluorescence states and solvent dependence of the emission.

A first goal was to determine whether a computational description also finds that the long wavelength fluorescence in pFNI and pFAQ is from the end traps. Does it predict that the charge-transfer state lies lower than the excited states in $\mathrm{pF}$ with significant oscillator strength? To accomplish this, we used recently developed long-range corrected (LC) functionals ${ }^{30,31}$ which are shown to be critical in correcting the error in conventional exchange-correlation functionals that leads to underestimation of the charge-transfer state energy. ${ }^{32,25,33}$. Table 3 presents the results from the LC- $\omega$ PBE functional that we recently found successful for polaron description in polyfluorenes in solution. ${ }^{34}$ It shows that the first excitation in $\mathrm{F}_{3} \mathrm{NI}\left(\mathrm{F}_{3} \mathrm{AQ}\right)$ has a lower energy than that in $\mathrm{F}_{3}$ or NI (AQ), suggesting it is charge transfer transition. Furthermore, it has significant oscillator strength that would allow fluorescence. We have carried out the same calculations with a different LC functional, CAM-B3LYP ${ }^{35}$, and reached the same conclusion, even though the computed excitation energies and oscillator strengths differ. However, because 
excited state geometry optimization with LC functionals is currently not implemented, we are not able to study the emission with these functionals, but we do not expect that the charge transfer transition will go above local transitions at its optimized geometry.

Table 3: TDDFT energies in $\mathrm{eV}$ and oscillator strengths (in parentheses) of the first three transitions for $\mathrm{F}_{3} \mathrm{NI}$ and $\mathrm{F}_{3} \mathrm{AQ}$, as well as for $\mathrm{F}_{3}, \mathrm{NI}$ and $\mathrm{AQ}$, all in the solvent THF. TDDFT calculations are performed at the geometry optimized in the ground state with the same functional, i.e LC- $\omega$ PBE with $\omega=0.1 \mathrm{bohr}^{-1}$. All calculations use the standard basis set 6-31G(d) and the PCM solvation with THF being the solvent.

\begin{tabular}{|l|l|l|l|l|}
\hline $\mathrm{F}_{3} \mathrm{NI}$ & $\mathrm{F}_{3} \mathrm{AQ}$ & $\mathrm{F}_{3}$ & $\mathrm{NI}$ & $\mathrm{AQ}$ \\
\hline 2.791 & 2.447 & 3.343 & 3.142 & 2.495 \\
$(0.9676)$ & $(0.2526)$ & $(2.5641)$ & $(0.0001)$ & $(0.0000)$ \\
\hline 3.127 & 2.507 & 3.910 & 3.466 & 2.770 \\
$(0.0048)$ & $(0.1026)$ & $(0.0168)$ & $(0.2122)$ & $(0.0000)$ \\
\hline 3.330 & 2.764 & 4.135 & 3.660 & 3.303 \\
$(1.5712)$ & $(0.0003)$ & $(0.0000)$ & $(0.0000)$ & $(0.0000)$ \\
\hline
\end{tabular}

The fact that the charge transfer transition is indeed the lowest-lying transition in $\mathrm{F}_{3} \mathrm{NI}$ and $\mathrm{F}_{3} \mathrm{AQ}$ also means that the underestimation errors for charge transfer states in conventional functionals become insignificant to a qualitatively correct description of these states. Therefore, we used B3LYP to probe the solvent-dependence of the emission energy, with the main purpose of identifying the trend. Following the well-described procedure for such studies from Gaussian manual $^{29}$, we were able to do TDDFT geometry optimization with equilibrium, linear-response solvation. ${ }^{36,37}$ It gives us the minimum energy point on the charge-transfer state potential energy surface in the solvent reaction field that corresponds to the ground state charge distribution. Comparing the charge transfer transition energy at this point in Table 4, a clear, albeit rather small, red shift is seen for the transition energy when the solvent changes from $p$-xylene to THF. More drastic solvent dependence of the emission energy, which was seen experimentally, can be expected with a state-specific equilibrium solvation of the excited state ${ }^{38,39}$, as also described in the manual. ${ }^{29}$ These calculations, however, could not converge for the charge transfer states that we are interested in. The equilibrium solvation effects of charge transfer states can also be probed by combining constrained $\mathrm{DFT}^{40}$ and $\mathrm{PCM}^{41}$ Here we attempt a different strategy ${ }^{42}$ in which the lowest triplet state, as calculated by unrestricted DFT, is used to approximate the charge distribution of the charge transfer state and hence, the equilibrium solvation effects. The Mulliken charge of the acceptor group in the triplet state (Table 4) indicates that such an approximation works better for $\mathrm{F}_{3} \mathrm{AQ}$ than for $\mathrm{F}_{3} \mathrm{NI}$, as could be anticipated from the greater $\mathrm{CT}$ 
character of the pFAQ triplet. ${ }^{43}$ The equilibrium solvation effect in $\mathrm{F}_{3} \mathrm{AQ}$ triplet is also stronger than in $\mathrm{F}_{3} \mathrm{NI}$ triplet and agrees better with the experimentally observed shift of the emission energy.

Table 4: TDDFT (B3LYP/6-31G*) energies in eV of the first transition for $\mathrm{F}_{3} \mathrm{NI}$ and $\mathrm{F}_{3} \mathrm{AQ}$ in the solvents THF and $p$-xylene. Geometries are optimized using TDDFT and linear-response solvation for the singlet excited states. Triplet energies are calculated with unrestricted DFT and reported relative to the singlet ground state at the same TDDFT optimized geometries. The numbers in parentheses are the Mulliken charge on the acceptor group (NI or AQ). The experimental shift is reported as the energy of maximum fluorescence emission intensity.

\begin{tabular}{|l|l|l|l|l|}
\hline & $\mathrm{F}_{3} \mathrm{NI}$ & $\mathrm{F}_{3} \mathrm{AQ}$ & $\mathrm{F}_{3} \mathrm{NI}$ triplet & $\mathrm{F}_{3} \mathrm{AQ}$ triplet \\
\hline THF & 2.209 & 1.747 & $2.029(-0.33)$ & $1.834(-0.77)$ \\
\hline$p$-xylene & 2.267 & 1.790 & $2.102(-0.22)$ & $2.115(-0.56)$ \\
\hline Shift & 0.058 & 0.057 & 0.073 & 0.281 \\
\hline Expt. shift & 0.42 & no & no & no \\
\hline
\end{tabular}

Intensity borrowing The intensity of charge transfer fluorescence may be understood through the interaction of the charge transfer state and the fluorescent local excited state of the $\mathrm{pF}$ chain. These two states together with the ground state form a three-state model that was originated in the theoretical treatment of Murrell ${ }^{44}$ and later extended by Bixon et al. ${ }^{45}$ Our zeroth order electronic states are $|\mathrm{pFA}\rangle,\left|\mathrm{pF}^{*} \mathrm{~A}\right\rangle$ and $\left|\mathrm{pF}^{+} \mathrm{A}^{-}\right\rangle$. Their energies are $0, E_{1}$ and $E_{\mathrm{ct}}$, respectively. The small electronic coupling between $\left|\mathrm{pF}^{+} \mathrm{A}^{-}\right\rangle$and the other two states are $V$ and $V^{*}$, respectively. Therefore, the ground state and the charge transfer state become, to the first order,

$$
\begin{aligned}
& |\mathrm{GS}\rangle=|\mathrm{pFA}\rangle+V / E_{\mathrm{ct}}\left|\mathrm{pF}^{+} \mathrm{A}^{-}\right\rangle, \\
& |\mathrm{CT}\rangle=\left|\mathrm{pF}^{+} \mathrm{A}^{-}\right\rangle-V / E_{\mathrm{ct}}|\mathrm{pFA}\rangle+V^{*} /\left(E_{1}-E_{\mathrm{ct}}\right)\left|\mathrm{pF}^{*} \mathrm{~A}\right\rangle .
\end{aligned}
$$

The transition dipole moment between these two states is then, again to the first order,

$$
\mu=\mu_{0}+V / E_{\mathrm{ct}} \Delta \mu+V^{*} /\left(E_{1}-E_{\mathrm{ct}}\right) \mu^{*}
$$

where $\mu_{0}$ is the transition dipole moment between $|\mathrm{pFA}\rangle$ and $\left|\mathrm{pF}^{+} \mathrm{A}^{-}\right\rangle, \Delta \mu$ is the difference between the permanent dipole moments of $\left|\mathrm{pF}^{+} \mathrm{A}^{-}\right\rangle$and $|\mathrm{pFA}\rangle$, and $\mu^{*}$ is the transition dipole moment between $|\mathrm{pFA}\rangle$ and $\left|\mathrm{pF}^{*} \mathrm{~A}\right\rangle . \mu_{0}$ depends on overlap between the initial and final states and is usually small for CT transitions. In the present case TDDFT calculations indicate that the CT states are principally (90\%) composed of configurations consisting of the HOMO and 
LUMO shown in Figure 5. The small overlap between these orbitals will make $\mu_{0}$ small. When $E_{\mathrm{ct}}$ is much larger than $V$, the second term is also small. In eq 3 the third term, which can be viewed as charge transfer state borrowing the intensity from local excited state, depends critically on the energy gap between the local excited state and the charge transfer state. The theory of intensity borrowing therefore predicts that radiative rates for fluorescence from the CT states will decrease as the energy of the CT state decreases. It explains why charge transfer fluorescence increases with lower solvent polarity because of the raised charge transfer state energy of pFA. The difference between pFNI and pFAQ may also be attributed to the fact that the former has a higher $E_{\mathrm{ct}}$, assuming similar coupling strengths.

$$
\mathrm{F}_{3} \mathrm{NI}
$$

HOMO

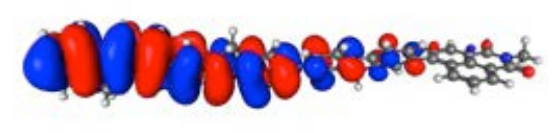

LUMO

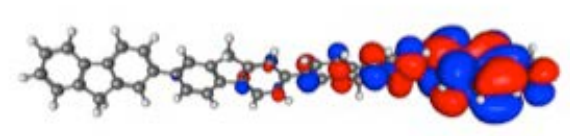

$\mathrm{F}_{3} \mathrm{AQ}$

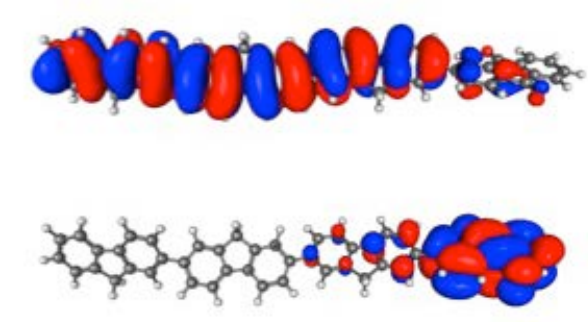

Figure 5 Orbitals that are mainly responsible for the charge transfer transition in $\mathrm{F}_{3} \mathrm{NI}$ and $\mathrm{F}_{3} \mathrm{AQ}$, plotted at the TDDFT (B3LYP/6-31G*) optimized geometries in linear-response PCM solvation. The solvent is THF; other solvents are not expected to change the picture much.

\section{Discussion}

Natures and Energies of Charge Transfer States. Figure 6 summarizes energetics for the fluorescent states in the chains and at the end traps. These data show that NI end groups form traps for excitons with depths of $0.14 \mathrm{eV}$ in p-xylene and $0.25 \mathrm{eV}$ in THF. The AQ group provides a $0.35 \mathrm{eV}$ trap in xylene; in THF and chloroform it is deeper, but no clear CT fluorescence spectrum was observed so the depth could not be determined. The difference with solvent polarity and the deeper trapping by AQ vs. NI both point to the CT nature of the end trapped exciton states. The broad, featureless fluorescence spectra in Figure 2 are typical of CT transitions. Figure 6 also shows that the energies of the end trapped excitons are below those of local excited states of NI and AQ, further supporting their CT character. Finally the CT nature 
of the end trapped states is confirmed by the TDDFT calculations in Table 3 and the orbitals involved in Figure 5.

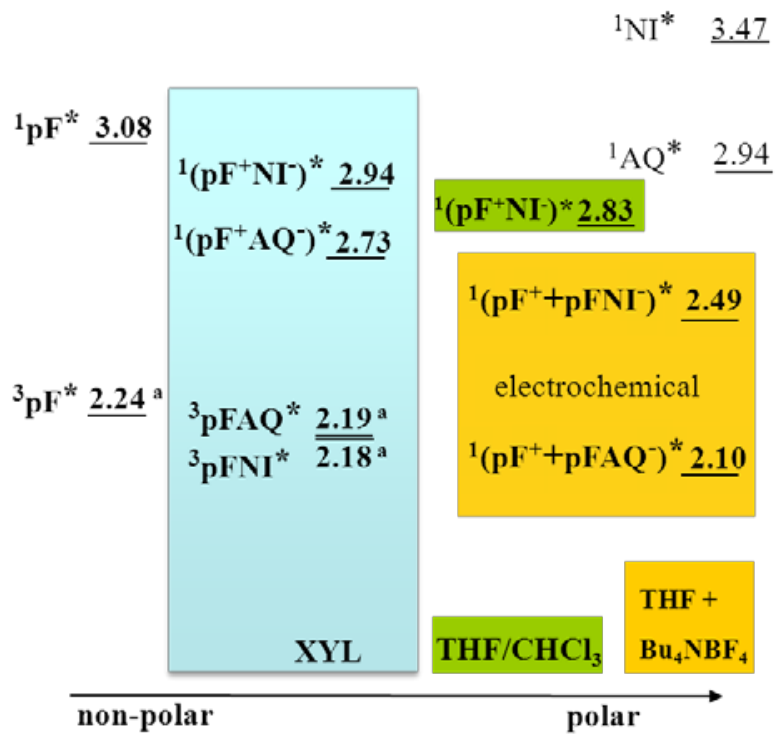

Figure 6. Energies (eV) of charge transfer band origins $\left(\mathrm{E}_{0}\right)$ in xylene (blue), THF and chloroform (green), compared to triplet energies ${ }^{a}$ from Sreearunothai ${ }^{43}$ and the energies of separate $\mathrm{pF}^{+\bullet}$ and $\mathrm{pFA}^{\bullet}$ from sums of redox potentials under electrochemical conditions (yellow) given in Table 5, from Asaoka. ${ }^{22}$

Electrochemical measurements ${ }^{22}$ provide redox potentials for formation of $\mathrm{pF}^{+} \bullet, \mathrm{pFNI}^{\bullet}$, and $\mathrm{pFAQ}^{-\bullet}$. Differences (eq 4 ) reported in Table 5 give free energies changes to form $\mathrm{pF}^{+\bullet}$ and $\mathrm{pFNI}^{\bullet}$ or $\mathrm{pF}^{+\bullet}, \mathrm{pFAQ}^{-\bullet}$.

$$
\Delta \mathrm{G}_{\mathrm{CS}}(0)=+\mathrm{E}^{0}\left(\mathrm{pF}^{+/ 0}\right)-\mathrm{E}^{0}\left(\mathrm{pFNI}^{0 /-}\right) \text { or AQ }
$$

These free energy changes are lower than the energies of CT states for pFNI in THF and chloroform. The separated ions measured electrochemically are expected to be stabilized due to the presence of $0.1 \mathrm{M}$ electrolyte. On the other hand they are expected to be destabilized because sums of electrochemical potentials refer to making ion-pairs at infinite distance. This comparison suggests that the stabilization of ions by the electrolyte is the stronger effect, but it may also indicate that in intimate ion pairs like $\mathrm{pF}^{+} \mathrm{NI}^{-}$with partly or nearly overlapping charge distributions both ions lose solvation energy and may encounter some kind of electronic destabilization in addition to the large Coulomb attraction between $\mathrm{pF}^{+}$and $\mathrm{NI}^{-}$. 
Table 5. Estimated energy of charge transfer bands from electrochemical potentials. ( $\mathrm{E}^{0} \mathrm{vs}$ $\mathrm{FC}^{+/ 0}$ )

\begin{tabular}{lcc}
\hline & $\mathrm{E}^{0}\left(\mathrm{pFA}^{0 /-}\right)^{\mathrm{a}}$ & $\mathrm{E}^{0}\left(\mathrm{pF}^{+/ 0}\right)-\mathrm{E}^{0}\left(\mathrm{pFA}^{0 /-}\right)$ \\
\hline pFNI & -1.831 & $2.491^{\mathrm{a}}$ \\
pFAQ & -1.437 & $2.097^{\mathrm{a}}$ \\
${ }^{\mathrm{a}}$ Redox potentials vs. $\mathrm{FC}^{+/ 0}$ in $\mathrm{THF}+0.1 \mathrm{M} \mathrm{Bu}_{4} \mathrm{NBF}_{4}$. \\
$\mathrm{E}^{0}\left(\mathrm{pF}^{+/ 0}\right)=+0.66^{22}$
\end{tabular}

Comparison to other CT states. Results presented here show behavior that contrasts with those of Neuteboom et al. ${ }^{46}$ who studied PFP, in which a single fluorene is capped by aperylene bisimide on both ends (PFP) (Chart 2). In PFP the locally excited state of the perylene bisimide (PERY) end trap is always the emitting state. The present molecules are similar in that CT states lie below a strongly emitting local excited state, $\mathrm{pF}$ in the present molecules and PERY in those of Neuteboom. The two cases are different in that in all solvents: Neuteboom sees no CT fluorescence, but finds the CT state to be below the local excited state of PERY* based on a decrease of PERY fluorescence as evidence of CT formation. With PFP* and PERY* very close in energy (PFP* 0.01eV lower) and below the local excited states, one would expect charge transfer states to form, but the absence of a CT fluorescence band leads to the conclusion that quenching of PERY fluorescence results from rapid intramolecular electron transfer from fluorene to PERY. The highly solvent dependent rates range from $~ 50 \mathrm{ps}$ in THF to 7 ns in toluene. Plausible reasons for the absence of charge transfer state fluorescence are that the CT band, if formed, could be outside the scanned wavelength region, or it may have very low intensity, possibly due to rapid non-radiative decay. Alternatively, the electronic coupling may be weak between the fluorene and PERY units. The NI and AQ end groups are directly conjugated to the $\mathrm{pF}$ chains, so $\mathrm{V}^{*}$ in eq 3 is large. Eq 3 therefore predicts strong intensity borrowing resulting in strong transition moments for radiative decay of the CT states of pFNI and pFAQ. In PFP the fluorene is bonded to PERY at the diimide nitrogen without direct conjugation. $V^{*}$ is therefore much weaker in PFP, so eq 3 predicts much less intensity borrowing and slow radiative decay. $V^{*}$ may be weakened further by the likelihood of a large dihedral angle between fluorene and PERY; a twisted conformation is supported by their UV-vis absorption 
spectra. The pFNIs in our study have stronger electronic coupling through conjugated bonds between the $\mathrm{pF}$ chain and the NI end cap, and the linkage at the NI aromatic ring rather than at the PERY saturated nitrogen bonds enables more overlap between the NI and pF subunits. Their system also differs from ours in that the PFP "chain" is very short; just one fluorene. Therefore, there is no need for transport. This distinction suggests evidence of delocalization of the positive charge in our molecules over several $\mathrm{pF}$ repeat units in the CT state. There is less Coulomb attraction in pFNI with the delocalized positive charge than in PFP.

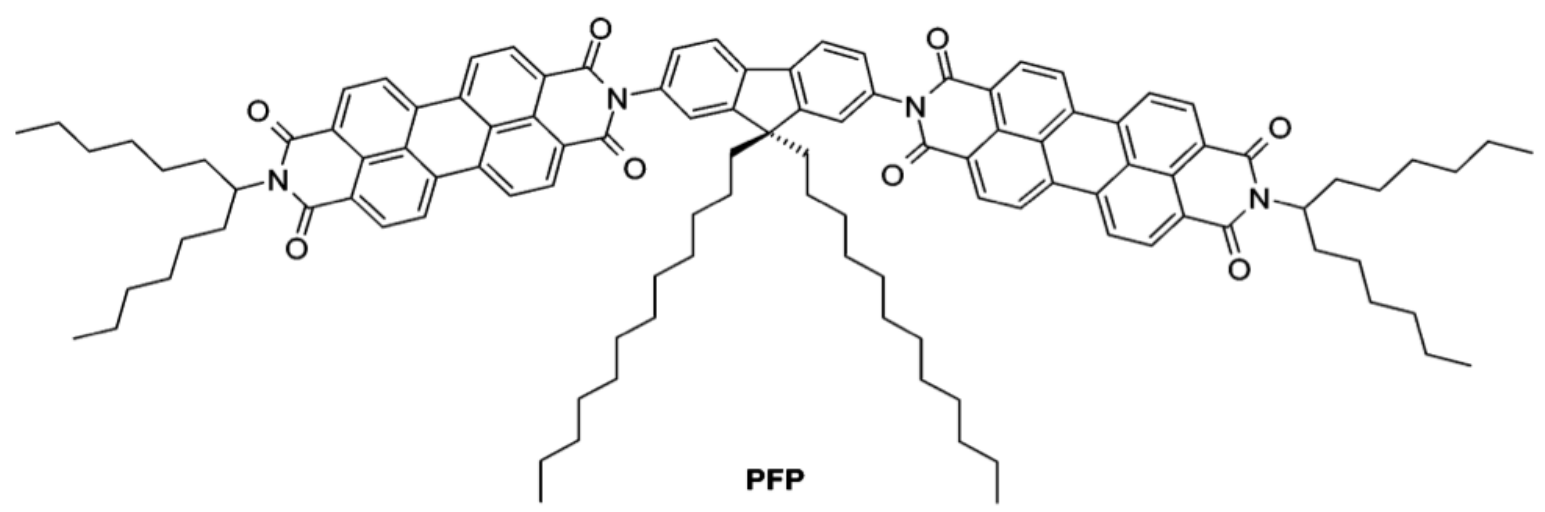

Chart 2. Structure of PFP. 2,7-bis(N-(1-hexylheptyl)-3,4:9,10-perylene-bisimide-N'-yl))-9,9didodecylfluorene.

\section{Transport to traps.}

Data in Table 2 and Figure 3 show that chain length is the primary factor determining how many excitons reach the end traps as measured by the fraction of chain fluorescence, $F_{\mathrm{c}}$. Varying the solvent from xylene to $\mathrm{THF}$ and $\mathrm{CHCl}_{3}$, appears to have little effect on $F_{\mathrm{c}}$. Neither does the nature of the end trap (NI vs AQ), although all of the changes alter the free energy change for the trapping process. Thus a first major finding is that exciton capture appears to be controlled by the rate of transport along the chains, not by the actual trapping process, which is likely to be diffusion-controlled, as suggested by Healy and coworkers ${ }^{8}$ in their thiophene fullerene molecules. Steady state fluorescence measurements on long chains composed of $>100$ repeat units in the present pFs suggest that end traps still capture $40-50 \%$ of excitons. 
Homogeneous Diffusion Model Fluorescence decays as $\mathrm{e}_{\mathrm{f}}^{-\mathrm{k}^{*}}$ in $\mathrm{pF}$ polymers without traps, with the lifetime of a $\mathrm{pF}$ exciton approximately $\mathrm{k}_{\mathrm{f}}^{-1}=400 \mathrm{ps}$. In end-capped polymers there is an additional decay that occurs if the exciton transports to the end trap group. Excitons in pF chains form polarons reported to be 5 repeat units in length based on convergence of fluorescence spectra of oligomers. ${ }^{34}$ From evidence noted above we may expect that excitons diffusing in the pF chains will be captured in every encounter with a trap group: capture will be diffusioncontrolled. Below the results will be used to examine this assumption. If excitons diffuse randomly along pF chains with diffusion-controlled capture at the traps, decay by reaction with the traps is expected ${ }^{7}$ to follow the known solution ${ }^{47,48}$ for diffusion with diffusion coefficient $\mathrm{D}$ to the ends of rods of length L. Eq 5 gives the probability, $\mathrm{P}(\mathrm{t})$, that a randomly diffusion exciton has survived capture by the traps.

$$
\mathrm{P}(\mathrm{t})=\frac{\sum_{n=0}^{\infty} \frac{1}{(2 n+1)^{2}} e^{\frac{-(2 n+1)^{2} \pi^{2} D t}{L^{2}}}}{\sum_{n=0}^{\infty} \frac{1}{(2 n+1)^{2}}}
$$

Eq 5 describes a multiexponential decay in which 82\% of the excitons decay by a single exponential that may be called the principal exponential, $\mathrm{k}_{\mathrm{p}}$, while the other $18 \%$ decay faster. Integration of eq 5 over $t$ would give the fraction of chain fluorescence, $\mathrm{F}_{\mathrm{c}}$, reported in Table 2. Eq 5 will be used below to describe homogeneous diffusion, but we note that the rate of decay might be approximated as a single exponential function with rate $\mathrm{e}_{\mathrm{f}}^{-\mathrm{k}^{*}}$. If it behaves as onedimensional diffusion to the end traps, the decay is multi-exponential. For an exciton of length $l_{\mathrm{ex}}$ the principal exponential, $k_{p}$, varies with the diffusion coefficient and the square of the length for chains with traps at both ends:

$$
\mathrm{k}_{\mathrm{p}}=\pi^{2} \mathrm{D} /\left(\mathrm{L}-\mathrm{l}_{\mathrm{ex}}\right)^{2} \quad(6 \mathrm{a}) \text {. }
$$

We refer to this as a "homogeneous diffusion model" because eq 5 assumes that diffusion occurs with a diffusion constant, $\mathrm{D}$, that is the same along the entire chain: the chain is homogeneous without significant defects that can disturb the diffusive motion. For a point particle (exciton of zero length) eq $6 a$ becomes $k_{p}=\pi^{2} \mathrm{D} /(\mathrm{L})^{2}$. Decay would be 4 times slower for chains with traps at one end compared to two ends:

$$
\mathrm{k}_{\mathrm{p}}=\pi^{2} \mathrm{D} / 4\left(\mathrm{~L}-\mathrm{l}_{\mathrm{p}}\right)
$$


With the approximation of a single exponential rate to the traps, $\mathrm{k}_{\mathrm{p}}$, these relations along with the known fluorescence lifetime of $\mathrm{k}_{\mathrm{f}}^{-1}=400$ ps can be used to predict the integrated fraction of excitons not captured, $\mathrm{F}_{\mathrm{c}}$. While the integrated form of eq 5 will be used below, eq 7 gives a simplified form of reasonable accuracy.

$$
\mathrm{F}_{\mathrm{c}}=\mathrm{k}_{\mathrm{f}} /\left(\mathrm{k}_{\mathrm{f}}+\mathrm{k}_{\mathrm{p}}\right)
$$

$\mathrm{F}_{\mathrm{C}}$ from integration of eq 5 can be compared to measured values of $\mathrm{F}_{\mathrm{C}}$ reported in Table 2 . A complication is that not all chains have the intended two trap groups. Recently the completeness of end capping was determined by measurements of triplet capture in the pFNI and pFAQ length fractions used here. ${ }^{49}$ The long lives of the triplets allowed them to move over the entire length of the chains. NMR measurements compared to multiangle light scattering (MALS) measurements were averaged over lengths giving a second measurement of $\mathrm{P}_{\text {cap }}$, which was accurate for shorter lengths ( $\mathrm{n}<60$ repeat units). Results of the two methods agreed to yield $\mathrm{P}_{\text {cap }},=0.73 \pm 0.1$ for pFNIs and $0.63 \pm 0.12$ for $\mathrm{pFAQ}$. $\mathrm{P}_{\text {cap }}$ showed a small variations with length, but these were within the uncertainties of the measurements. Here we will assume these values do not depend on length. Assuming random capping (one end does not know about the other during synthesis), the fractions of chains with two, one and zero trap groups are $\mathrm{P}_{2}=\mathrm{P}_{\text {cap }}{ }^{2}, \mathrm{P}_{1}=$ $2 \mathrm{P}_{\text {cap }}\left(1-\mathrm{P}_{\text {cap }}\right)$ and $\mathrm{P}_{0}=\left(1-\mathrm{P}_{\text {cap }}\right)^{2}$.

We follow Healy ${ }^{8}$ in integrating diffusion equations over distributions of lengths in each polymer fraction. Figure 7a) shows a fit of $F_{c}$ with length in pFNI, with $F_{c}$ determined by integration of eq 5 in which each data point is averaged over the distribution of lengths in that polymer fraction using the distributions from MALS given in Figure 7b). The weight fraction distribution is used as longer chains have a higher probability of absorbing a photon to form an exciton. Using the measured $\mathrm{P}_{\text {cap }}=0.73,{ }^{49}$ the fit describes the data well giving $\mathrm{D}=0.037 \pm 0.004$ $\mathrm{cm}^{2} / \mathrm{s}$, where uncertainties are from fits. The fit results are given as points that compare well to the measurements. The dashed line in Figure 7a) shows a similar fit without averaging over distributions of length. For each of the nine points the length $\mathrm{L}$ in eq 5 is set to the average length for that polymer fraction. The resulting dashed line gives a poor description of the data, highlighting the need to consider the polymer length distributions. Figure S5 shows similar fits for a range of values for completeness of capping, $\mathrm{P}_{\text {cap }}$. These fits, which do not take length distributions into account, give reasonable descriptions only with $\mathrm{P}_{\text {cap }}=0.5-0.6$, which is far lower than the previously reported value. They give somewhat larger values of the diffusion 
coefficient, $\mathrm{D}=0.099 \mathrm{~cm}^{2} / \mathrm{s}$ and $0.04 \mathrm{~cm}^{2} / \mathrm{s}$. The value $\mathrm{D}=0.037 \mathrm{~cm}^{2} / \mathrm{s}$ from the fit with distributions is considered much more reliable.
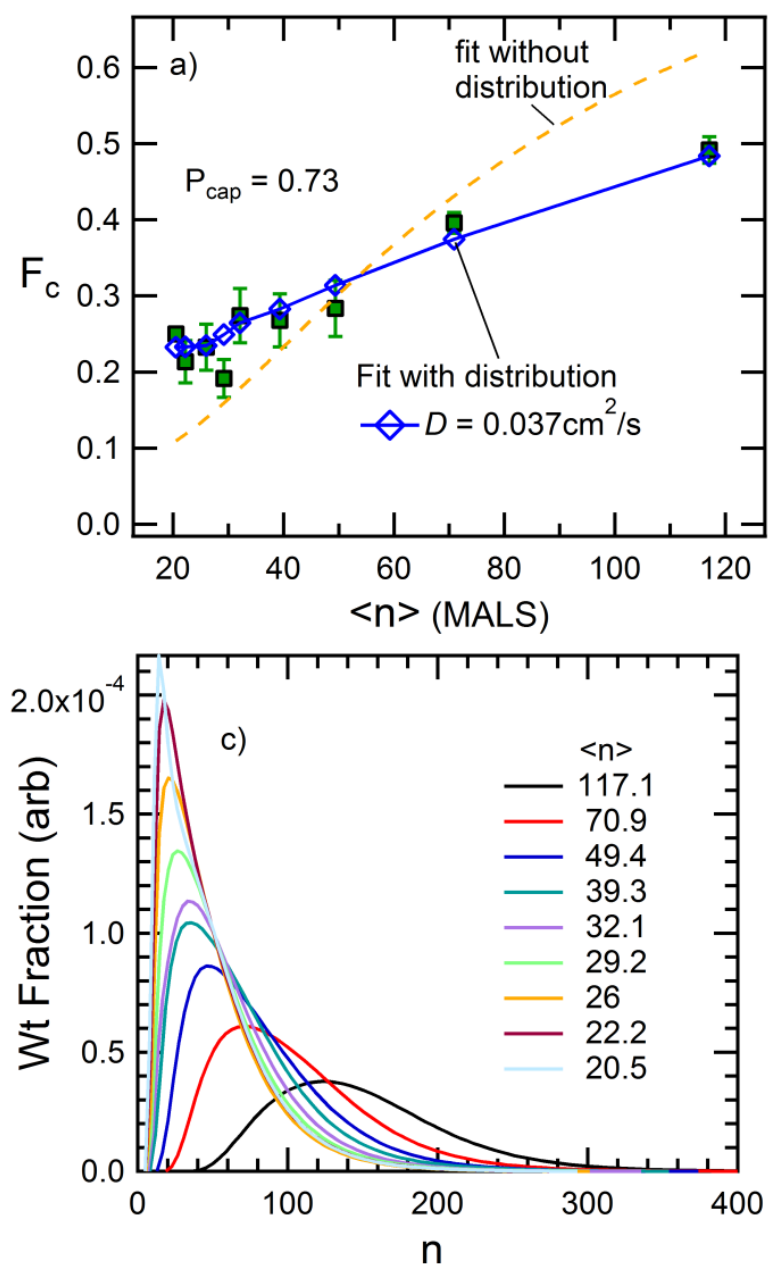

Figure 7. Chain fluorescence fits for pFNI in THF using the one-dimensional homogeneous diffusion model of eq 5. a) Chain fractions $F_{c}$ with fit points $(\diamond)$ obtained by integrating eq 5 over the length distributions shown in b). An alternative fit assumes that each polymer fraction is monodisperse with a length $=<\mathrm{n}>$. Both fits use an end capping probability, $\mathrm{P}_{\text {cap }}=0.73$. The superior fit with averaging over length distributions, gave a diffusion coefficient $\mathrm{D}=0.037 \mathrm{~cm} / \mathrm{s}$.

Data and fits for the pFNIs similar to those in Figure 7a) in three different solvents (Figure S6) give diffusion coefficients, $\mathrm{D}=0.025$ (xylene), 0.037 (THF) and $0.025 \mathrm{~cm}^{2} / \mathrm{s}$ $\left(\mathrm{CHCl}_{3}\right)$. The average over the three solvents is $0.029 \mathrm{~cm}^{2} / \mathrm{s}$. In fluorene oligomers with $\mathrm{C}_{60}$ end traps Shibano found $\mathrm{D}=5.9-8.5 \times 10^{-3} \mathrm{~cm}^{2} / \mathrm{s}$, about four times smaller. From $\mathrm{D}=0.029 \mathrm{~cm}^{2} / \mathrm{s}$ and 
$\tau=400$ ps the diffusion length, $L_{D}=(D \tau)^{1 / 2}=34 \mathrm{~nm}$ can be estimated. While THF and chloroform are moderately polar liquids, p-xylene in nearly nonpolar. Additional differences are that pxylene has conjugated $\pi$ orbitals while the other two do not, and is a somewhat poorer solvent. An important aspect of the present results is that the exciton transport does not seem to be influenced by changes in the polarity the medium or whether it contains saturated or $\pi$ bonds. While it is conceivable that effects of these different properties might partly cancel, the similarity of results in the three solvents implies that exciton transport is nearly independent of these properties.

While the homogeneous diffusion model described appears to explain measurements of exciton capture here and those by fullerene traps on polythiophene chains, ${ }^{8}$ other types of measurement of excitons in polymer chains are often interpreted by assuming that the chains are not homogeneous but are divided into segments. ${ }^{5,6,50,51}$ A very simple model based on this idea is shown schematically in Figure 8. In this simple model excitons diffuse freely until they encounter some kind of defect. Near each end trap the excitons can diffuse to reach the trap from an average distance covering $n_{D}$ repeat units. Excitons farther than $n_{D}$ units from a trap are sufficiently slowed that they do not reach the trap within their lifetime.

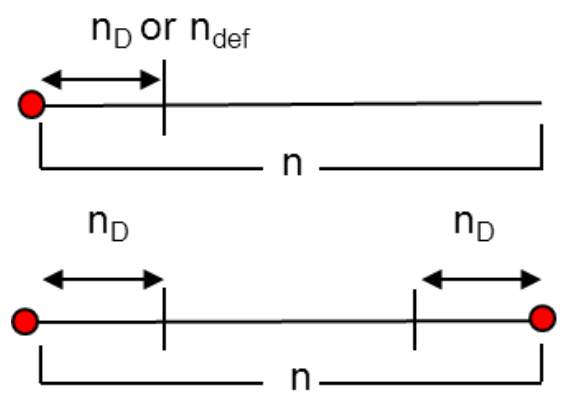

Figure 8. A polymer chain with a length of $n$ repeat units having either one or two end traps $n_{D}$ is the diffusion length of an exciton within its lifetime. Alternatively, for discussion of a model of defects, that length is $\mathrm{n}_{\text {def }}$, the distance in repeat units to the defect closest to the trap.

If only excitons near to trap groups are captured, as suggested in Figure 8, then the fraction giving chain fluorescence, is $F_{C}=\left(n-2 n_{D}\right) / n$ for doubly-capped chains and $F_{C}=\left(n-n_{D}\right) / n$ for singly-capped chains. At the simplest level the diffusion length, $\mathrm{n}_{\mathrm{D}}$ repeat units, is the same for every chain. Fits of the observed chain fluorescence intensities to this description (not shown) are not good and display discontinuities inherent in this somewhat artificial model. This model, 
an alternative to that of homogeneous diffusion, assumes that capture occurs only near the traps. This behavior could arise if exciton capture involved direct exciton transfer to the traps, without transport, such as by long-distance Förster transfer. But the large values of $n_{D}, 26-106$ repeat units (22-88 nm), are too large for such direct transfer.

The picture in Figure 8 also defines a type of diffusional capture length $\mathrm{n}_{\mathrm{c}}$ in repeat units derived from the fractions of chain fluorescence in a chain of length $n$ units as $n_{c}=n(1$ $\left.\mathrm{F}_{\mathrm{c}}\right) /\left(2 \mathrm{P}_{\text {cap }}{ }^{2}+2 \mathrm{P}_{\text {cap }}\left(1-\mathrm{P}_{\text {cap }}\right)\right)$ and $l_{\mathrm{c}}=0.83 \mathrm{n}_{\mathrm{c}}$ for $\mathrm{pF}$ chains. Figure 9 plots the capture lengths (per trap group) defined in this way for data in pFNI and pFAQ chains. These capture lengths are small for shorter chains, being confined by chain lengths. For longer chains they approach the diffusion length, $\mathrm{L}_{\mathrm{D}}=34 \mathrm{~nm}$ estimated above.

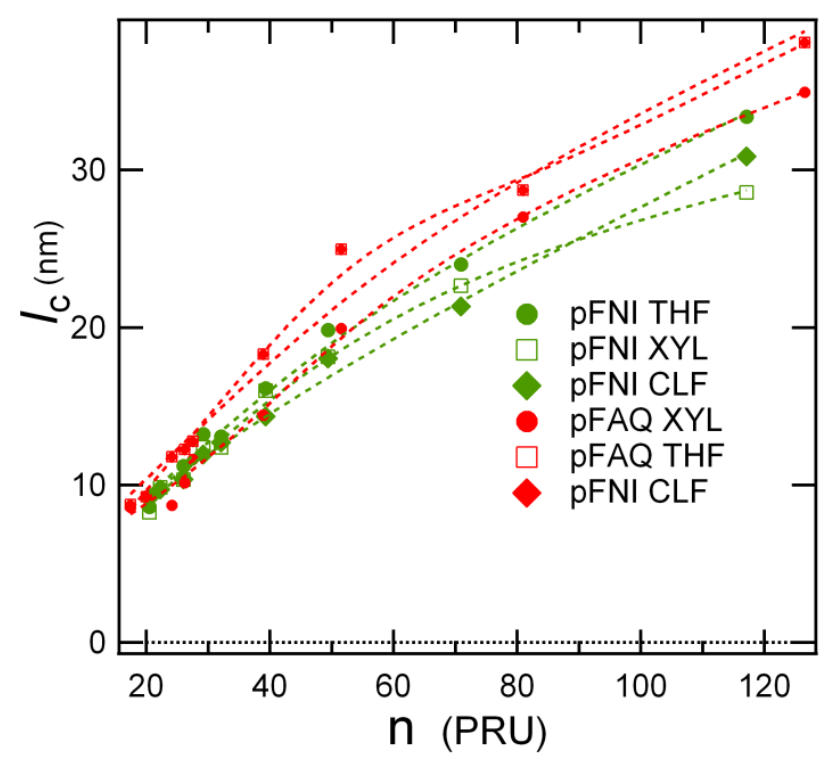

Figure 9. Diffusional capture lengths $l_{c}$ vs chain length for pFNI and pFAQ, each in three solvents, THF, p-xylene and chloroform..

Figure 8 can also describe a model based on defects. The simplest such model assumes that exciton diffusion occurs readily along the chain, but is halted by a defect. With this assumption, the traps capture excitons formed in the segments of length $\mathrm{n}_{\mathrm{def}}$ near the traps, but excitons formed at longer lengths can not be captured. $\mathrm{n}_{\text {def }}$ is therefore the distance from the trap to the nearest defect. $\mathrm{n}_{\text {def }}$ is not constant. It is different for each chain determined by probability. Assuming that the defects are randomly placed with an average density $\rho_{d}$ (and average spacing 
of $\rho_{\mathrm{d}}{ }^{-1}$ ) then the probability that the defect nearest to a trap is located $\eta$ repeat units from the trap is $P(\eta)=\rho_{d}\left(1-\rho_{d}\right)^{\eta-1}$. Then for chains with $\kappa=1$ or 2 end trap groups, the surviving chain fluorescence is

$$
F_{c}=\sum_{\eta \leq n / \kappa} P(\eta)\left(\frac{n-\kappa \eta}{n}+\frac{\kappa \eta}{n} \frac{k_{p}}{k_{p}+n}\right)
$$

In eq $8 \kappa=1$ for a singly capped chain; the $n-\eta$ units farther than the defect fluoresce normally and the $\eta$ units near the trap group are quenched by the factor $k_{f} /\left(k_{f}+k_{p}\right)$. The principal exponential, $\mathrm{k}_{\mathrm{p}}$, is related to the exciton diffusion coefficient, $\mathrm{D}$, by eq $6 \mathrm{~b}$, to describe diffusion in a segment with a trap group at one end and a reflecting defect at the other. For a doubly capped chain, $\kappa=2$, eq 8 approximates $\eta_{1}+\eta_{2}=2 \eta$. This will underestimate exciton capture because for different lengths to the first defect $\left(\eta_{1} \neq \eta_{2}\right)$ there could be more capture.

Figure 10 displays fits of the defect model to chain fractions for pFNI in THF. The fit curve describes the data well within its noise.

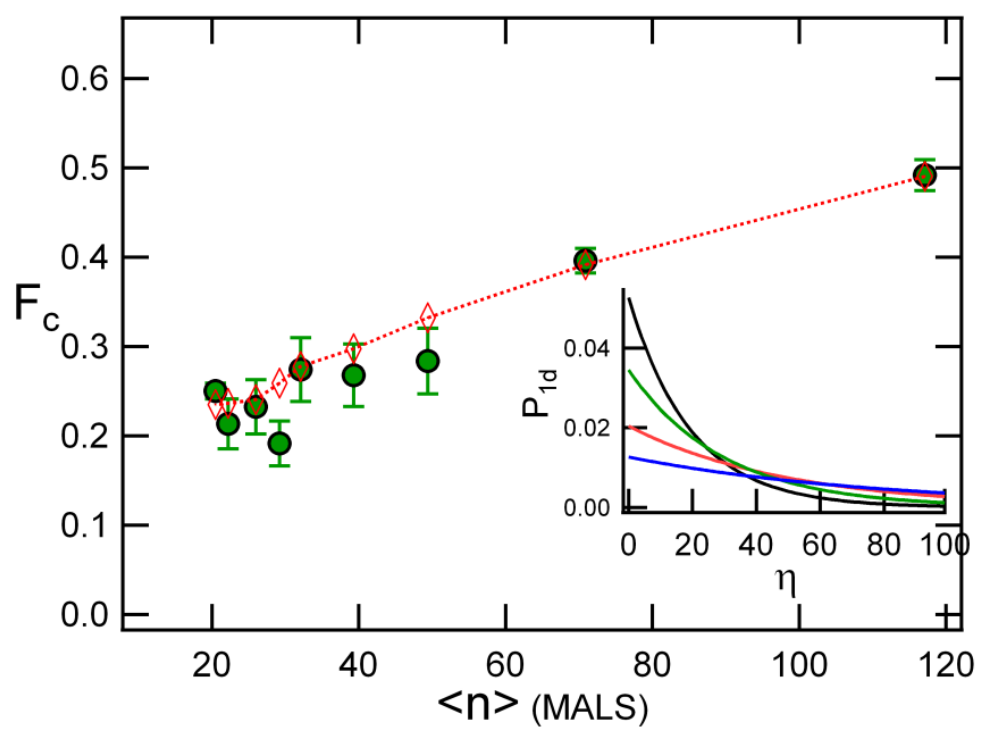

Figure 10. Fractions of chain fluorescence for pFNI inTHF fit by the defect model (eq 8) with averaging over distributions. The fits gave an average defect spacings of 75 repeat units. $P_{\text {cap }}=0.73$ (pFNI) was fixed during the fit. The inset plots the probability, $P(\eta)=\rho_{d}\left(1-\rho_{d}\right)^{\eta-1}$. that the closest defect is $\eta$ repeat units from the trap for average defect spacings of 20, 30, 50 and 80 repeat units. 
The defect model fit in Figure 10 does not allow the exciton to move freely along the entire chain. It gives average diffusional capture lengths, $l_{\mathrm{c}}=32,27$ and $26 \mathrm{~nm}$ from the fits to the three data sets in Figures 10 and S6 for long polymer fractions. These are shorter than $\mathrm{L}_{\mathrm{D}}=34$ $\mathrm{nm}$ estimated from the diffusion coefficient obtained in the fits by homogeneous diffusion. These capture lengths are shorter than the average defect spacings of 65, 49, and 46 repeat units, (or 54, 41 and $38 \mathrm{~nm}$ ) because the distribution of probabilities of closest defects is skewed toward short lengths as seen in the inset to Figure 10. In this defect description the capture length is determined by the defect spacing; the fits are nearly independent of the diffusion coefficient over a large range so $\mathrm{D}$ is not determined by the fits. The fits to eq 8 used $\mathrm{D}=0.02 \mathrm{~cm}^{2} / \mathrm{s}$. Slightly better fits were found for larger diffusion coefficients, but we capped D to a value ${ }^{7}$ near to that found for homogeneous diffusion.

The defect model used here describes the data reasonably well, as does the homogeneous diffusion model. Other defect-based descriptions might as well. It gives diffusion lengths that are roughly similar to those of the homogeneous diffusion model. The simple model of eq 8 assumes the defects to be impermeable barriers. More sophisticated models could allow some permeability or even include a range of barriers or alternatively shallow traps. The present data with nine length fractions provides valuable tests, but could likely be fit by a range of models and would not be likely to distinguish between them. At present the homogeneous diffusion model, applied to take distributions of length into account, is the simplest of the models that describe the data well.

\section{Conclusions}

Naphthylimide (NI) and anthraquinone (AQ) end traps directly conjugated to the ends of polyfluorene chains serve as traps for excitons created by excitation of the chains in solution. The trap depths ranging from 0.06 to $>0.27 \mathrm{eV}$, vary with solvent polarity and trap group. End trapped excitons often give strong CT fluorescence with CT states at energies that lie above those of separated ions in electrochemical conditions. CT state quantum yields per trapped exciton are as high as $64 \%$, or $46 \%$ per absorbed photon. The very intense CT fluorescence is understood in terms of intensity borrowing. CT fluorescence is less intense in polar solvents, showing that non-radiative decay is favored as the energy of the polar CT excited state is 
lowered in polar solvents. It also reflects less effective intensity borrowing in polar solvents where the CT state lies farther below the pF chain excited state. The large shift in pFNI charge transfer fluorescence energy as a function of solvent polarity $(0.2 \mathrm{eV})$ suggests a considerable dipole moment in the CT excited state as compared to the $\mathrm{pF}$ excited state with its small solvent effect energy shift $(0.02 \mathrm{eV})$. This results in weak CT fluorescence in polar solvents for $\left(\mathrm{pF}^{+} \mathrm{AQ}^{-}\right.$ ), which is expected to have lower energy than $\left(\mathrm{pF}^{+} \mathrm{NI}^{-}\right)$.

The probability of exciton capture by the end traps depends on chain length, but is independent of 1) trap depth, 2) solvent polarity and 3) which trap group is used. These findings point to diffusion-controlled capture of excitons by both trap groups, as might be expected because the NI and AQ traps are intimately connected to the chains by conjugated links. Diffusion-controlled capture means that properties of the chains, not the end traps, determine the rates of exciton capture so the present results tell us that exciton transport along the chains is not affected by the surrounding medium. The steady state fluorescence results reported here can be modeled by homogeneous $1 \mathrm{D}$ diffusion along the chains to give an exciton diffusion length of 34 nm, or by a model based on occasional defects.

A goal of this work was to assess the potential of conjugated chains to act as "molecular wires" that could act as antennae to funnel excitons to donor-acceptor junctions in OPV cells. Such cells are typically 100-200 nm thick, so even if conjugated chains could be aligned to transport excitons to junctions, the $34 \mathrm{~nm}$ diffusion length found here may not resoundingly suggest that there are alternatives to living with the short exciton diffusion lengths reported in films. But it is a substantial step in the right direction and a notable improvement on what is known. The $L_{D}=34 \mathrm{~nm}$ found here substantially exceeds diffusion lengths near $7 \mathrm{~nm}$ in polymer films, ${ }^{9-14}$ also $7 \mathrm{~nm}$ for transport along polythiophene chains ${ }^{8}$ and $20 \mathrm{~nm}$ found in crystalline poly-(3-hexyl)thiophene (P3HT) domains. ${ }^{52}$ It may therefore be a record-setting diffusion length for singlet exciton transport in organic polymers.

\section{Experimental Section}

Chemicals. Tetrahydrofuran, xylene, chloroform, dimethylformamide, and polystyrene were used as received from Aldrich. The synthesis of $\mathrm{pF}_{24}$ to $\mathrm{pF}_{136}, \mathrm{pF}_{21} \mathrm{NI}$ to $\mathrm{pF}_{117} \mathrm{NI}$, and 
$\mathrm{pF}_{17} \mathrm{AQ}$ to $\mathrm{pF}_{127} \mathrm{AQ}$ was described previously. ${ }^{22,53} \cdot \mathrm{pF}, \mathrm{pFNI}$, and $\mathrm{pFAQ}$ with $\mathrm{M}_{\mathrm{N}}=19 \pm 2 \mathrm{kD}$ were each separated into nine fractions by preparative gel permeation chromatography. Multi-angle light scattering was used to determine the average polymer lengths within each fraction. The average number of end caps per chain end was estimated by NMR to be, $\mathrm{P}_{\text {cap }}=0.81 \pm 0.04$ (pFNI) and $0.74 \pm 0.07$ (pFAQ) for fractions <40 units in length; accuracy is low for longer fractions. Measurements of triplet capture suggest slightly smaller values $\mathrm{P}_{\text {cap }}=0.74 \pm 0.04(\mathrm{pFNI})$ and $0.63 \pm 0.06$ (pFAQ).

Spectroscopy. pF, pFNI, and pFAQ solutions that gave UV-visible absorbencies of 0.05 were prepared in chloroform, dimethylformamide (DMF), tetrahydrofuran (THF), and xylene. Concentrations were $10^{-7}$ to $10^{-8} \mathrm{M}$. Ultraviolet-visible absorption spectroscopy was performed at room temperature from 200-600 nm on a Shimadzu 3600 spectrometer using $1.0 \mathrm{~cm}$ pathlength quartz spectrophotometric cells. Ground state UV-visible absorption spectra for polymers of length $\mathrm{pF}_{24}$ to $\mathrm{pF}_{136}, \mathrm{pF}_{21} \mathrm{NI}$ to $\mathrm{pF}_{117} \mathrm{NI}$, and $\mathrm{pF}_{17} \mathrm{AQ}$ to $\mathrm{pF}_{127} \mathrm{AQ}$ in chloroform, dimethylformamide (DMF), tetrahydrofuran (THF), and xylene show absorption maxima at 387$390 \mathrm{~nm}$ in THF and 384-390nm in chloroform (Table S1). DMF maxima are red shifted (398410nm) and broader (Figure S1); xylene maxima are blue shifted (381-387nm). Extinction coefficients range from $1 \times 10^{6}$ to $4 \times 10^{6} \mathrm{M}^{-1} \mathrm{~cm}^{-1}$. Corrected steady state fluorescence emission spectra were obtained from 380-700nm in $1.00 \mathrm{~cm}$ pathlength dry quartz cells on a Horiba JobinYvon Fluoromax 4 with excitation at 380nm and slit width of $1.0 \mathrm{~nm}$. Spectral data were processed using IGOR Pro (Wavemetrics).

Computations. Gaussian $09^{29}$ was employed to perform calculations using linear response time-dependent density functional theory (TDDFT) ${ }^{26,27}$ in conjunction with the polarizable continuum model (PCM) for solvation. ${ }^{28}$ The model compounds were fluorene trimers with one end capped by either an NI or AQ group.

Supporting Information Available: UV-visible absorption data, absorption and fluorescence spectra in DMF, chain fluorescence fits using one-dimensional diffusion models. This material is available free of charge via the Internet at http://pubs.acs.org.

\section{Author Information}

Corresponding Author: zaikowskium@gmail.com 
Notes: The authors declare no competing financial interest.

\section{Acknowledgments}

Research carried out in part at the Center for Functional Nanomaterials, Brookhaven National Laboratory, which is supported by the U.S. Department of Energy, Office of Basic Energy Sciences, under Contract No. DE-AC02-98CH10886. The authors gratefully acknowledge support of the Division of Chemical Sciences, Geosciences, and Biosciences, Office of Basic Energy Sciences of the U.S. Department of Energy through Grant No. DE-AC02-98CH10886 to all authors. We thank Melissa Farrell of Dowling College who carried out preliminary experiments, and Xiang Li of Brookhaven National Laboratory for experiments to determine the percent of uncapped pFA. Partial support was provided by the National Science Foundation's Robert Noyce Teacher Scholarship Program at Dowling College to LZ, MF, BK, and GM under Award No. 03-35799 and 09-34814. Any opinions, findings, and conclusions or recommendations expressed in this material are those of the authors and do not necessarily reflect the views of the National Science Foundation. LZ and GM thank Noel Blackburn of the BNL Office of Educational Programs for his leadership and support in the U.S. Department of Energy Faculty and Student Team (FaST) Program. LZ acknowledges support from Dowling College Release Time for Research.

\section{References}

(1) Hoppe, H.; Sariciftci, N. S. In Photoresponsive Polymers Ii; Marder, S. R., Lee, K. S., Eds. 2008; Vol. 214, p 1-86.

(2) Winder, C.; Sariciftci, N. S., Low Bandgap Polymers for Photon Harvesting in Bulk Heterojunction Solar Cells, J. Mater. Chem. 2004, 14, 1077-1086.

(3) Halls, J. J. M.; Walsh, C. A.; Greenham, N. C.; Marseglia, E. A.; Friend, R. H.; Moratti, S.

C.; Holmes, A. B., Efficient Photodiodes from Interpenetrating Polymer Networks, Nature 1995, 376, 498-500.

(4) Yu, G.; Gao, J.; Hummelen, J. C.; Wudl, F.; Heeger, A. J., Polymer Photovoltaic Cells Enhanced Efficiencies Via a Network of Internal Donor-Acceptor Heterojunctions, Science 1995, 270, 1789-1791.

(5) Beljonne, D.; Pourtois, G.; Silva, C.; Hennebicq, E.; Herz, L. M.; Friend, R. H.; Scholes, G. D.; Setayesh, S.; Mullen, K.; Bredas, J. L., Interchain Vs. Intrachain Energy Transfer in Acceptor-Capped Conjugated Polymers, Proc. Nat. Acad. Sci. USA 2002, 99, 10982-10987. 
(6) Hennebicq, E.; Pourtois, G.; Scholes, G. D.; Herz, L. M.; Russell, D. M.; Silva, C.; Setayesh, S.; Grimsdale, A. C.; Mullen, K.; Bredas, J. L.et. al., Exciton Migration in Rigid-Rod Conjugated Polymers: An Improved Forster Model, J. Am. Chem. Soc. 2005, 127, 4744-4762.

(7) Shibano, Y.; Imahori, H.; Sreearunothai, P.; Cook, A. R.; Miller, J. R., Conjugated "Molecular Wire" for Excitons, J. Phys. Chem.Lett. 2010, 1, 1492-1496.

(8) Healy, A. T.; Boudouris, B. W.; Frisbie, C. D.; Hillmyer, M. A.; Blank, D. A., Intramolecular Exciton Diffusion in Poly(3-Hexylthiophene), J. Phys. Chem.Lett. 2013, 4, 34453449.

(9) Lewis, A. J.; Ruseckas, A.; Gaudin, O. P. M.; Webster, G. R.; Burn, P. L.; Samuel, I. D. W., Singlet Exciton Diffusion in Meh-Ppv Films Studied by Exciton-Exciton Annihilation, Org. Electron. 2006, 7, 452-456.

(10) Mikhnenko, O. V.; Cordella, F.; Sieval, A. B.; Hummelen, J. C.; Blom, P. W. M.; Loi, M. A., Temperature Dependence of Exciton Diffusion in Conjugated Polymers, J. Phys. Chem. B 2008, 112, 11601-11604.

(11) Shaw, P. E.; Ruseckas, A.; Samuel, I. D. W., Exciton Diffusion Measurements in Poly(3Hexylthiophene), Adv. Mater. 2008, 20, 3516-+.

(12) Markov, D. E.; Tanase, C.; Blom, P. W. M.; Wildeman, J., Simultaneous Enhancement of Charge Transport and Exciton Diffusion in Poly(P-Phenylene Vinylene) Derivatives, Phys. Rev. B 2005, 72.

(13) Scully, S. R.; McGehee, M. D., Effects of Optical Interference and Energy Transfer on Exciton Diffusion Length Measurements in Organic Semiconductors, J. Appl. Phys. 2006, 100. (14) Mikhnenko, O. V.; Azimi, H.; Scharber, M.; Morana, M.; Blom, P. W. M.; Loi, M. A., Exciton Diffusion Length in Narrow Bandgap Polymers, Energy \& Environmental Science 2012, 5, 6960-6965.

(15) Barford, W.; Bittner, E. R.; Ward, A., Exciton Dynamics in Disordered Poly(PPhenylenevinylene). 2. Exciton Diffusion, J. Phys. Chem. A 2012, 116, 10319-10327.

(16) Zalesskaya, G. A.; Blinov, S. I., Delayed Fluorescence of Anthraquinone, Activated by Multiphoton Vibrational Excitation of Triplet Molecules, Sov. Phys. Kokl. 1985, 30, 297-299.

(17) Montalti, M.; Credi, A.; Prodi, L.; Gandolfi, M. T. Handbook of Photochemistry 3rd ed.; CRC Press,Taylor and Francis Group: Boca Raton, FL,. 2006.

(18) Wintgens, V.; Valat, P.; Kossanyi, J.; Biczok, L.; Demeter, A.; Berces, T., Spectroscopic Properties of Aromatic Dicarboximides. Part1.-N-H and N-Methyl-Substituted Naphthalimides, J. Chem. Soc., Faraday Trans. 1994, 90, 411-421.

(19) Borisevich, N. A.; Zalesskaya, G. A.; Urbanovich, A. E., Delayed Luminescence Induced by Multiple Photon Excitation of Ground Electronic State Polyatomic Molecules with Carbon Dioxide Laser, Spectrosc. Lett. 1990, 23, 405-24.

(20) Gololobov, A. E.; Dorokhin, A. V.; Zalesskaya, G. A., Vibrational Relaxation of Triplet Molecules at High Vibrational Excitation Levels, Dokl. Akad. Nauk BSSR 1986, 30, 708-11.

(21) Zalesskaya, G. A.; Blinov, S. A., Vibrational Excitation of Anthraquinone Triplet Molecules by Carbon Dioxide Laser Radiation in the Absence of Collisions, Dokl. Akad. Nauk SSSR 1985, 281, 1102-5 [Phys.].

(22) Asaoka, S.; Takeda, N.; Iyoda, T.; Cook, A. R.; Miller, J. R., Electron and Hole Transport to Trap Groups at the Ends of Conjugated Polyfluorenes, J. Am. Chem. Soc. 2008, 130, 1191211920. 
(23) Penfield, K. W.; Miller, J. R.; Paddon-Row, M. N.; Cotsaris, E.; Oliver, A. M.; Hush, N. S., Optical and Thermal Electron Transfer in Rigid Difunctional Molecules of Fixed Distance and Orientation, J. Am. Chem. Soc. 1987, 109, 5061-5.

(24) Morris, J. V.; Mahaney, M. A.; Huber, J. R., Fluorescence Quantum Yield Determinations. 9,10-Diphenylanthracene as a Reference Standard in Different Solvents, The Journal of Physical Chemistry 1976, 80, 969-974.

(25) Lakowicz, J. R. Principles of Fluorescence Spectroscopy; 3rd ed.; Springer: New York, NY, 2006.

(26) Casida, M. E. In Recent Advances in Density Functional Methods: Part 1; Chong, D. P., Ed.; World Scientific: 1995, p 155.

(27) Bauernschmitt, R.; Ahlrichs, R., Treatment of Electronic Excitations within the Adiabatic Approximation of Time Dependent Density Functional Theory, Chem. Phys. Lett. 1996, 256, 454-464.

(28) Tomasi, J.; Mennucci, B.; Cammi, R., Quantum Mechanical Continuum Solvation Models., Chem. Rev. 2005, 105, 2999-3093.

(29) Gaussian 09, v. A.1, Frisch, M. J.; Trucks, G. W.; Schlegel, H. B.; Scuseria, G. E.; Robb, M. A.; Cheeseman, J. R.; Scalmani, G.; Barone, V.; Mennucci, B.; Petersson, G. A.et. al., 2009. (30) Savin, A. In Recent Advances in Density Functional Methods, Part 1; Chong, D. P., Ed.; World Scientific: 1995, p 129.

(31) Vydrov, O. A.; Scuseria, G. E., Assessment of a Long-Range Corrected Hybrid Functional., J. Chem. Phys. 2006, 125, 234109.

(32) Rohrdanz, M. A.; Martins, K. M.; Herbert, J. M., A Long-Range-Corrected Density Functional That Performs Well for Both Ground-State Properties and Time-Dependent Density Functional Theory Excitation Energies, Including Charge-Transfer Excited States, The Journal of chemical physics 2009, 130, 054112-054112-8.

(33) Rohrdanz, M. A.; Herbert, J. M., Simultaneous Benchmarking of Ground- and ExcitedState Properties with Long-Range-Corrected Density Functional Theory, The Journal of Chemical Physics 2008, 129, -.

(34) Zaikowski, L.; Kaur, P.; Gelfond, C.; Selvaggio, E.; Asaoka, S.; Wu, Q.; Chen, H. C.; Takeda, N.; Cook, A. R.; Yang, A.et. al., Polarons, Bipolarons, and Side-by-Side Polarons in Reduction of Oligofluorenes, J. Am. Chem. Soc. 2012, 134, 10852-10863.

(35) Yanai, T.; Tew, D. P.; Handy, N. C., A New Hybrid Exchange-Correlation Functional Using the Coulomb-Attenuating Method (Cam-B3lyp), Chem. Phys. Lett. 2004, 393, 51-57.

(36) Scalmani, G.; Frisch, M. J., Continuous Surface Charge Polarizable Continuum Models of Solvation. I. General Formalism., The Journal of chemical physics 2010, 132, 114110.

(37) Scalmani, G.; Frisch, M. J.; Mennucci, B.; Tomasi, J.; Cammi, R.; Barone, V., Geometries and Properties of Excited States in the Gas Phase and in Solution: Theory and Application of a Time-Dependent Density Functional Theory Polarizable Continuum Model, The Journal of chemical physics 2006, 124, 094107.

(38) Improta, R.; Barone, V.; Scalmani, G.; Frisch, M. J., A State-Specific Polarizable Continuum Model Time Dependent Density Functional Theory Method for Excited State Calculations in Solution, The Journal of chemical physics 2006, 125, 054103-054103-9. (39) Improta, R.; Scalmani, G.; Frisch, M. J.; Barone, V., Toward Effective and Reliable Fluorescence Energies in Solution by a New State Specific Polarizable Continuum Model Time Dependent Density Functional Theory Approach, J. Chem. Phys. 2007, 127. 
(40) Wu, Q.; Van Voorhis, T., Direct Optimization Method to Study Constrained Systems within Density-Functional Theory, Phys. Rev. A 2005, 72, 024502.

(41) Zheng, S.; Phillips, H.; Geva, E.; Dunietz, B. D., Ab Initiostudy of the Emissive ChargeTransfer States of Solvated Chromophore-Functionalized Silsesquioxanes, J. Am. Chem. Soc. 2012, 134, 6944-6947.

(42) Liu, T.; Troisi, A., Absolute Rate of Charge Separation and Recombination in a Molecular Model of the P3ht/Pcbm Interface, J. Phys. Chem. C 2011, 115, 2406-2415.

(43) Sreearunothai, P.; Estrada, A.; Asaoka, S.; Kowalczyk, M.; Jang, S.; Cook, A. R.; Preses, J. M.; Miller, J. R., Triplet Transport to and Trapping by Acceptor End Groups on Conjugated Polyfluorene Chains, J. Phys. Chem. C 2011, 115, 19569-19577.

(44) Murrell, J. N., Molecular Complexes and Their Spectra. Ix. The Relationship between the Stability of a Complex and the Intensity of Its Charge-Transfer Bands1, J. Am. Chem. Soc. 1959, 81, 5037-5043.

(45) Bixon, M.; Jortner, J.; Verhoeven, J. W., Lifetimes for Radiative Charge Recombination in Donor-Acceptor Molecules, J. Am. Chem. Soc. 1994, 116, 7349-7355.

(46) Neuteboom, E. E.; Meskers, S. C. J.; Beckers, E. H. A.; Chopin, S. p.; Janssen, R. A. J., Solvent Mediated Intramolecular Photoinduced Electron Transfer in a Fluorene-Perylene Bisimide Derivative, The Journal of Physical Chemistry A 2006, 110, 12363-12371.

(47) Carslaw, H. S.; Jaeger, J. C. Conduction of Heat in Solids; 2nd ed.; Oxford University Press, USA: New York, 1986.

(48) Zachmanoglou, E. C.; Thoe, D. W. Introduction to Partial Differential Equations with Applications; Dover Publications, 1987.

(49) Liang Xi, M. B., † Gina Mauro, † Sadayuki Asaoka, §, Andrew R. Cook, † Hung-Cheng Chen, $\dagger \ddagger$ and John R. Miller, Continuous Transport of Triplet Excitons Along 100 Nm Polyfluorene Chains, J. Phys. Chem., submitted 2014.

(50) Nguyen, T. Q.; Wu, J. J.; Doan, V.; Schwartz, B. J.; Tolbert, S. H., Control of Energy Transfer in Oriented Conjugated Polymer-Mesoporous Silica Composites, Science 2000, 288, 652-656.

(51) Hwang, I.; Scholes, G. D., Electronic Energy Transfer and Quantum-Coherence in PiConjugated Polymers, Chem. Mater. 2011, 23, 610-620.

(52) Tamai, Y.; Matsuura, Y.; Ohkita, H.; Benten, H.; Ito, S., One-Dimensional Singlet Exciton Diffusion in Poly(3-Hexylthiophene) Crystalline Domains, J. Phys. Chem.Lett. 2014, 5, 399-403. (53) Klaerner, G.; Miller, R. D., Polyfluorene Derivatives: Effective Conjugation Lengths from Well-Defined Oligomers, Macromolecules 1998, 31, 2007-2009. 


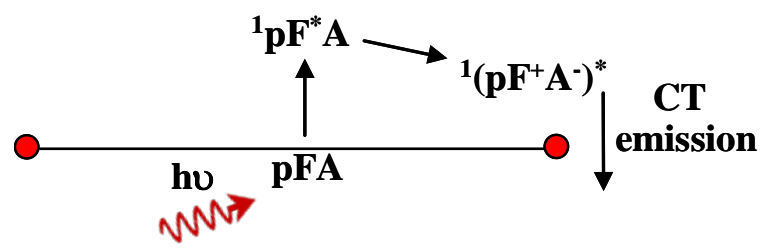

Table of Contents Graphic. 


\section{Supporting Information for: Charge Transfer Fluorescence and 34 nm Exciton Diffusion Length in Polymers with Electron Acceptor End Traps}

Lori Zaikowski, ${ }^{1,2^{*}}$ Gina Mauro, ${ }^{1,2}$,Matthew Bird, ${ }^{2}$ Brianne Karten ${ }^{1}$, Sadayuki Asaoka ${ }^{2, \dagger}$, Qin $\mathrm{Wu}^{3}$, Andrew R. Cook, ${ }^{2}$ and John R. Miller ${ }^{2 *}$

Table S1. Wavelengths of maximum UV-vis absorption for $\mathrm{pF}_{\mathrm{n}}, \mathrm{pF}_{\mathrm{n}} \mathrm{NI}$, and $\mathrm{pF}_{\mathrm{n}} \mathrm{AQ}$ in xylene (XYL), chloroform $\left(\mathrm{CHCl}_{3}\right)$, tetrahydrofuran (THF), and dimethylformamide (DMF). $\mathrm{n}=$ average number of repeat units for each fraction separated by preparatory gel permeation chromatography.

\begin{tabular}{lcccc} 
Polymer & XYL $(\mathrm{nm})$ & $\mathrm{CHCl}_{3}(\mathrm{~nm})$ & $\mathrm{THF}(\mathrm{nm})$ & $\mathrm{DMF}(\mathrm{nm})$ \\
\hline $\mathrm{pF}_{24}$ & 381 & 384 & 388 & 390 \\
$\mathrm{pF}_{28}$ & 384 & 388 & 388 & 395 \\
$\mathrm{pF}_{30}$ & 384 & 388 & 389 & 399 \\
$\mathrm{pF}_{32}-\mathrm{pF}_{34}$ & 385 & 388 & 389 & 400 \\
$\mathrm{pF}_{45}$ & 385 & 389 & 390 & 400 \\
$\mathrm{pF}_{57}-\mathrm{pF}_{84}$ & 386 & 389 & 390 & 402 \\
$\mathrm{pF}_{136}$ & 387 & 390 & 390 & 402 \\
$\mathrm{pFNI}_{21}$ & 386 & 388 & 388 & 395 \\
$\mathrm{pFNI}_{22}-\mathrm{pF}_{50}$ & 386 & 389 & 390 & $396-402$ \\
pFNI $_{71}-\mathrm{pFNI}_{117}$ & 387 & 389 & 390 & 402 \\
pFAQ $_{17}$ & 385 & 384 & 387 & 390 \\
pFAQ $_{20}$ & 385 & 385 & 388 & 393 \\
PFAQ $_{24}$ & 385 & 388 & 389 & 394 \\
pFAQ $_{26}-\mathrm{pFAQ}_{28}$ & 386 & 388 & 389 & 399 \\
pFAQ $_{39}-\mathrm{pFAQ}_{52}$ & 386 & 389 & 390 & 400 \\
pFAQ $_{81}$ & 387 & 389 & 390 & 402 \\
pFAQ $_{127}$ & 386 & 390 & 390 & 402
\end{tabular}




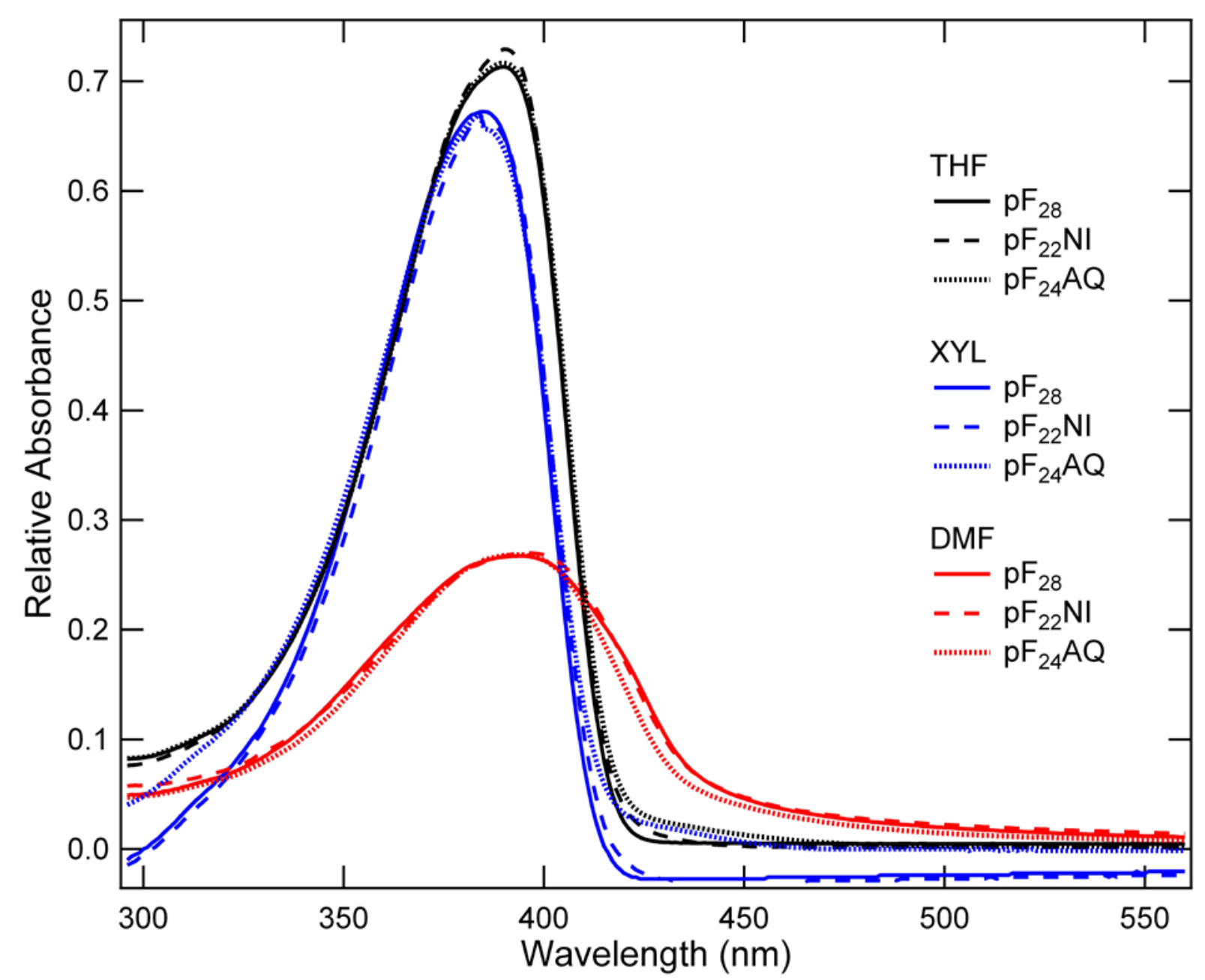

Figure S1. Steady state UV-vis absorption spectra for $\mathrm{pF}_{28}, \mathrm{pF}_{22} \mathrm{NI}$, and $\mathrm{pF}_{24} \mathrm{AQ}$ in THF, xylene, and DMF in $1 \mathrm{~cm}$ pathlength quartz cells. $3 \times 10^{-7} \mathrm{M}$ concentration based on sample mass and MALS average mw. Chloroform spectra, not shown; are almost identical to THF spectra. Note intensity differences among pF, pFNI, and pFAQ spectra in a given solvent. The absorption (and emission) blue shift in xylene is likely due to an increased dihedral angle between monomers, causing reduced pi overlap and a shorter effective conjugation length. ${ }^{1}$ In DMF the absorption peak shifted red and broadens, which could signal longer conjugation length and more planarity between monomers. Samples in DMF have lower absorption at a given concentration than THF or xylene samples, and lower fluorescence than THF or xylene samples with the same absorption at the excitation wavelength, indicating inter- or intra-chain aggregation., ${ }^{2,3}$ 


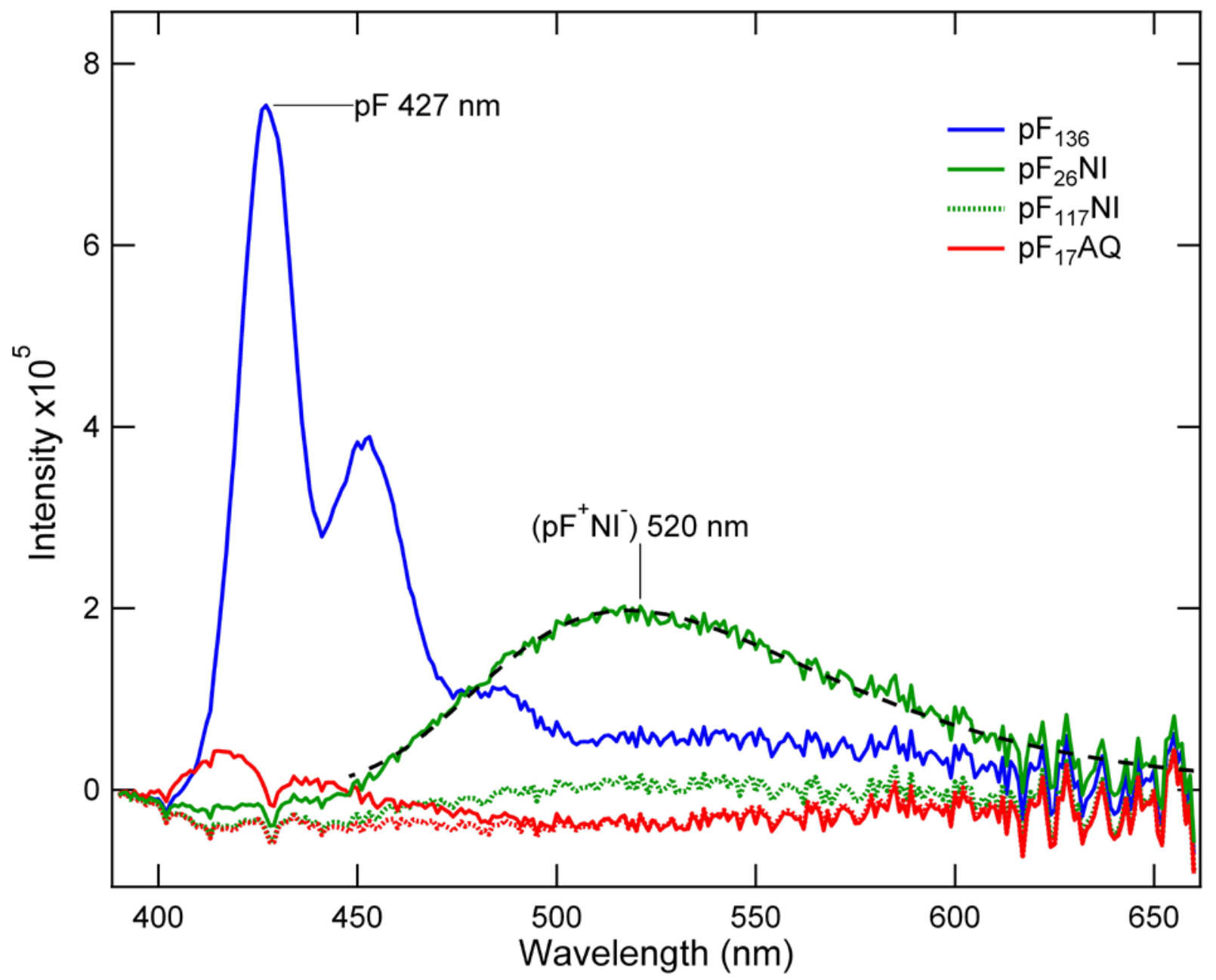

Figure S2. Steady state fluorescence of pF, pFNI, and pFAQ in DMF. Note pF intensity is 3040 times smaller in DMF than in xylene, chloroform or THF. In $\mathrm{pF}_{26} \mathrm{NI}$, pF chain intensity is zero and only $\left(\mathrm{pF}^{+} \mathrm{NI}^{-}\right)$charge transfer fluorescence is observed. In $\mathrm{pF}_{26} \mathrm{NI},\left(\mathrm{pF}^{+} \mathrm{NI}^{-}\right)$charge transfer fluorescence intensity is $\sim 37$ times smaller in DMF than in THF. pFAQ shows little pF chain fluorescence and no charge transfer fluorescence. The fit (black dashed line) for $\mathrm{pF}_{26} \mathrm{NI}$ in DMF gave $\mathrm{E}_{0} \mathrm{CT}=2.85, \lambda_{\mathrm{s}}=0.38 \mathrm{eV}$, and $\lambda_{\mathrm{V}}=0.14 \mathrm{eV}$ using eq $\mathrm{S} 1$.

Equation $\mathrm{S}^{4}$ describes the contour of a charge transfer band $\mathrm{I}=\mathrm{I}_{0}\left(4 \pi \lambda_{\mathrm{s}} k_{B} T\right)^{-1 / 2} \sum_{\mathrm{w}=0}^{\infty}\left(\mathrm{e}^{-\mathrm{s}} \frac{\mathrm{S}^{\mathrm{w}}}{\mathrm{w} !}\right) \exp \left\{-\left[\left(\lambda_{s}+\Delta G^{o}+w h v\right)^{2} / 4 \lambda_{s} k_{B} T\right]\right\}$ 


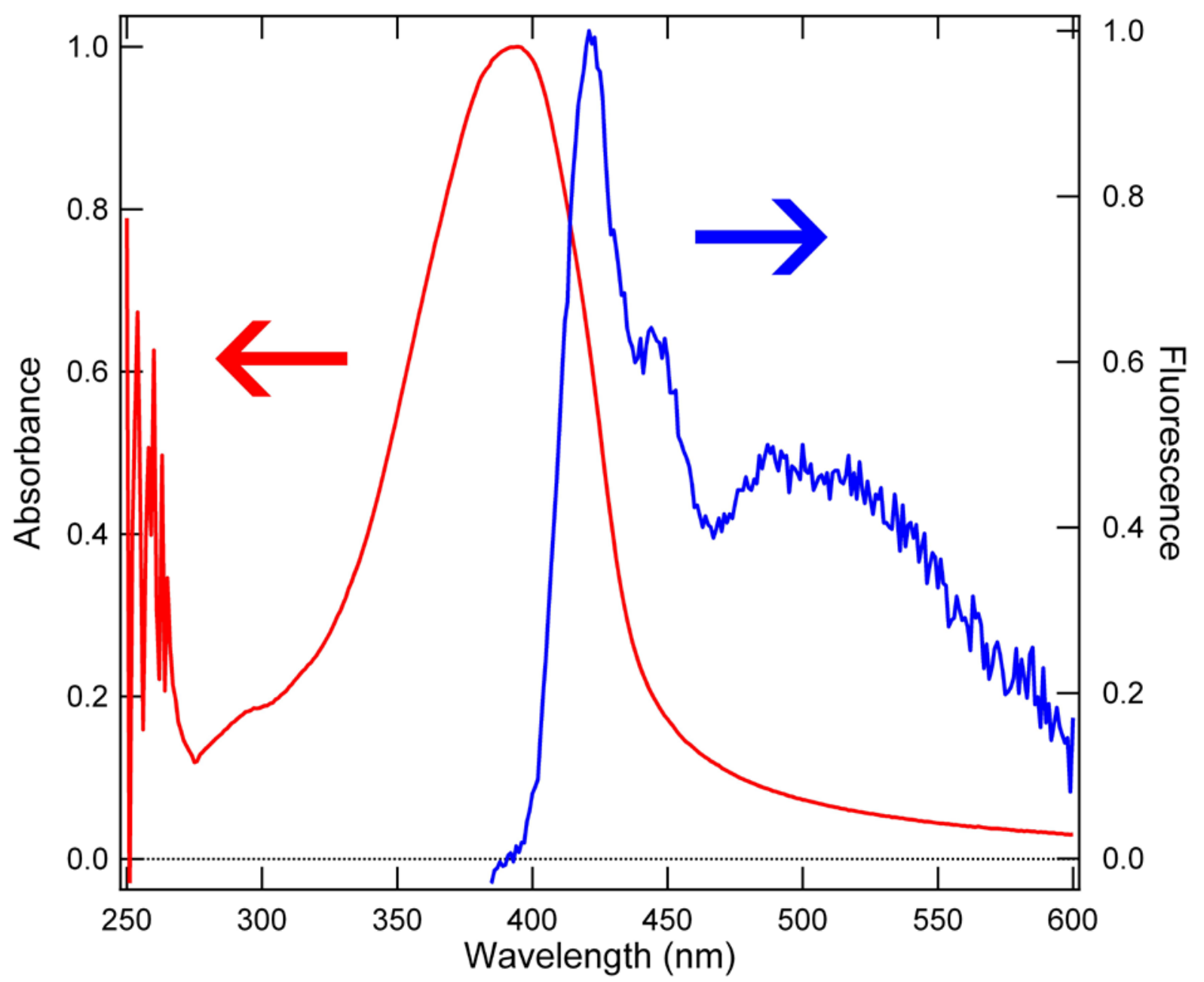

Figure S3a. Absorption and fluorescence intensity of $\mathrm{pF}_{28}$ in $\mathrm{DMF}$. 


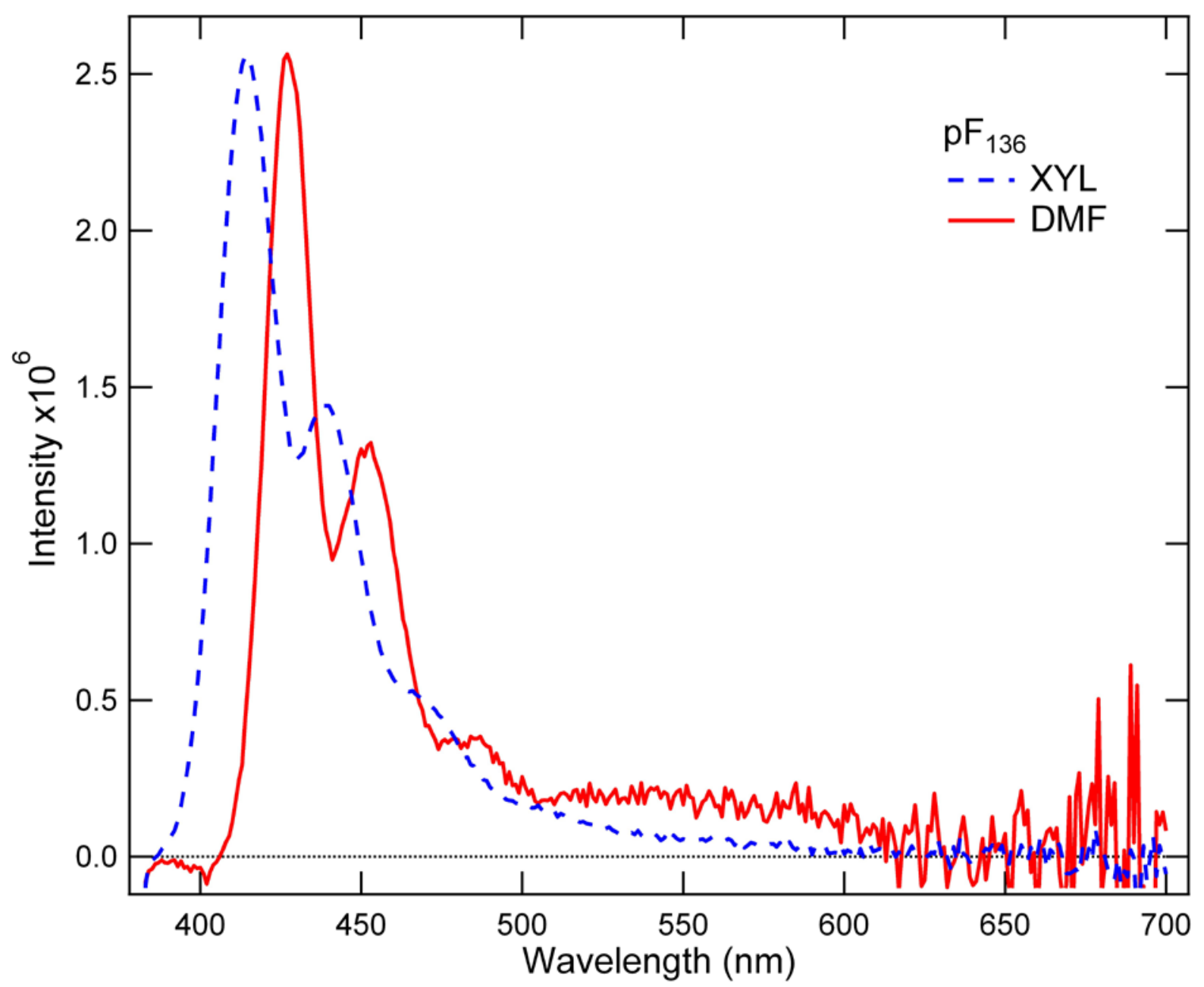

Figure S3b). Fluorescence intensity of $\mathrm{pF}_{117}$ in $\mathrm{p}$-xylene and DMF. The intensity in DMF was multiplied by 3.4 . 


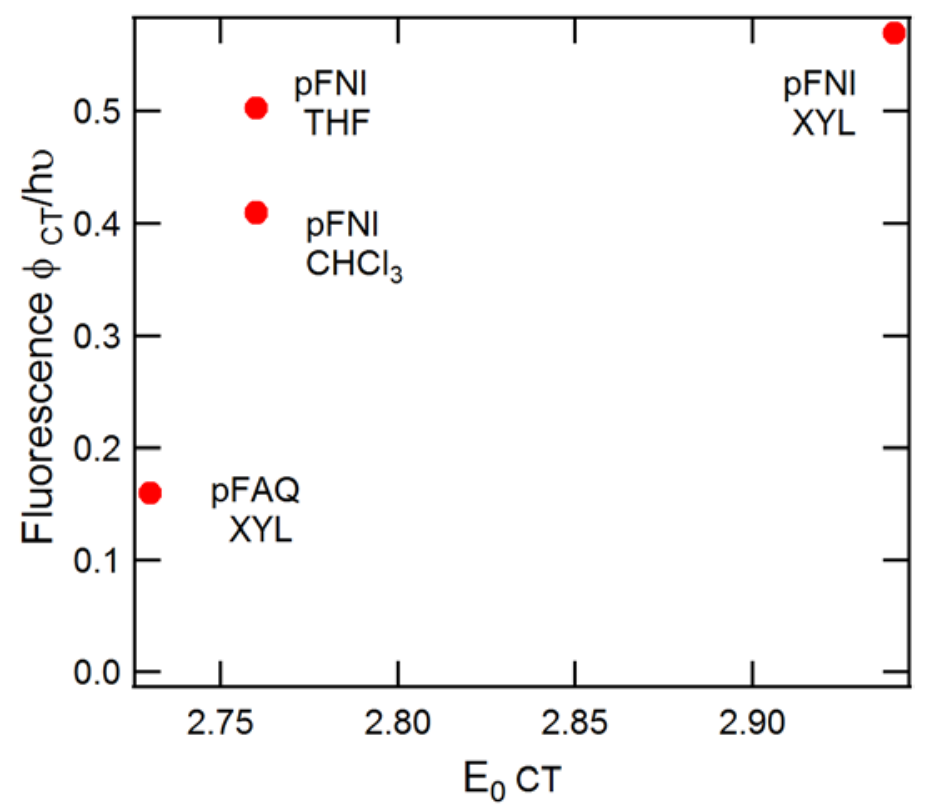

Figure S4. Average charge transfer state quantum yields per trapped exciton ( $\left.\phi_{\mathrm{CT} / \mathrm{exT}}\right)$ plotted as a function of charge transfer state energy $\left(\mathrm{E}_{0} \mathrm{CT}\right)$. 


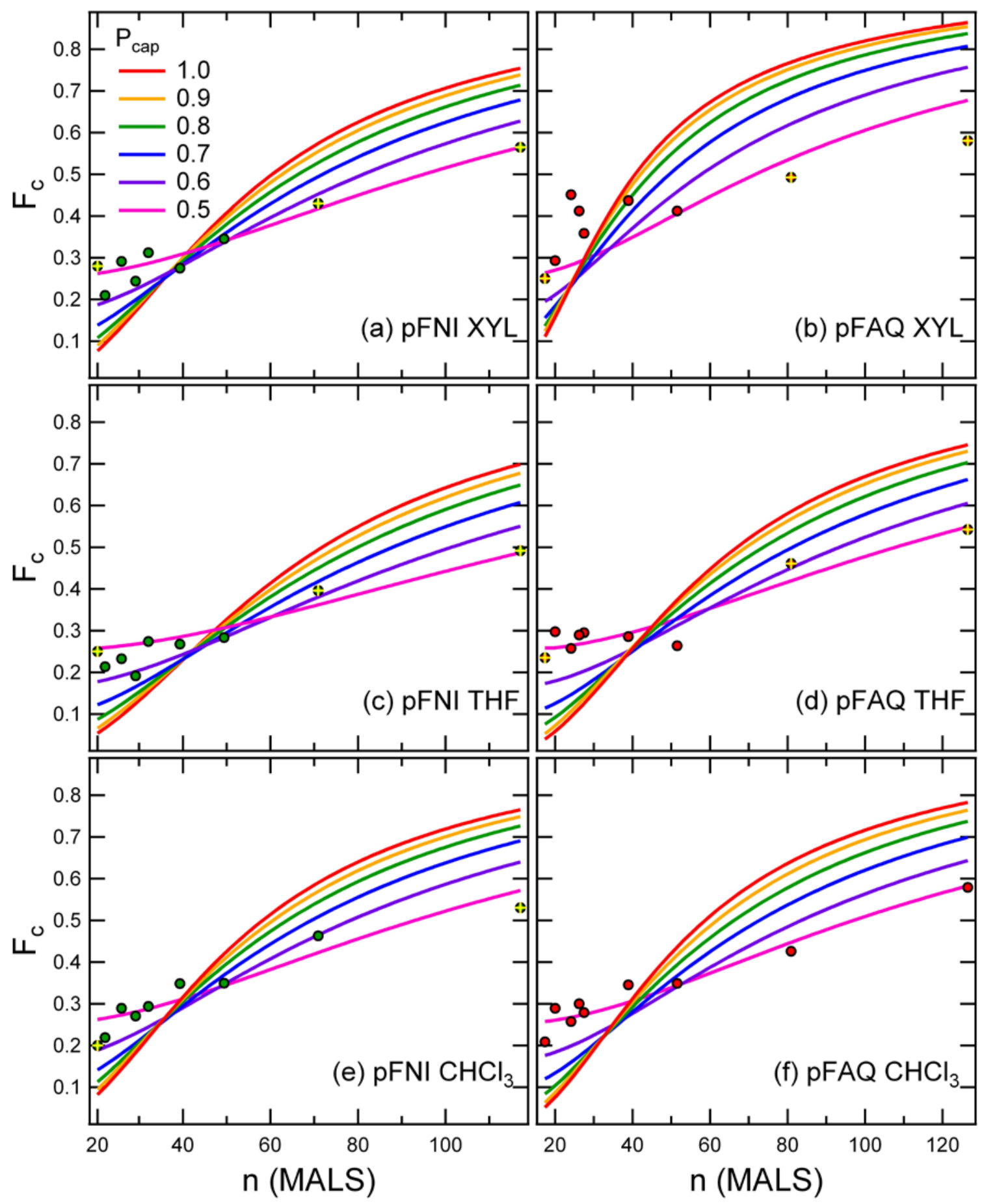

Figure S5. The observed fraction of chain fluorescence, $F_{c}$, with fits to the homogeneous diffusion model (eqs 5-6) for pFA in xylene, THF, and chloroform with varying capping fractions. These fits like that if Figure 7a) use the average lengths of each polymer fraction, not taking into account the distribution of lengths in each polymer fraction. $\mathrm{P}_{\text {cap }}$ is the probability that a chain end has a trap group. 
Table S2. Diffusion lengths ( $\mathrm{n}_{\mathrm{D}}$ ) for pFNI and $\mathrm{pFAQ}$ in xylene, THF, and chloroform. $\mathrm{n}_{\mathrm{D}}=(\pi \mathrm{D} \tau)^{1 / 2}$, where $\mathrm{D}$ is the diffusion coefficient determined from the one-dimensional diffusion model, and $\tau$ is the lifetime of an exciton.

\begin{tabular}{ccccccc}
\hline $\mathrm{P}_{\text {cap }}$ & pFNI XYL & pFNI THF & pFNI CHCl $_{3}$ & pFAQ XYL & pFAQ THF & pFAQ CHCl \\
\hline 1.0 & 21.6 & 26.1 & 20.7 & 13.7 & 24.2 & 20.9 \\
0.9 & 25.4 & 31.1 & 24.5 & 16.2 & 28.4 & 25.0 \\
0.8 & 31.2 & 38.2 & 29.9 & 20.0 & 35.0 & 31.1 \\
0.7 & 40.2 & 49.9 & 38.6 & 26.5 & 45.9 & 40.7 \\
0.6 & 55.9 & 70.9 & 53.8 & 38.5 & 65.0 & 57.7 \\
0.5 & 85.2 & 111.4 & 83.3 & 62.9 & 97.5 & 87.1
\end{tabular}

Table S3. $\mathrm{E}_{\mathrm{T}}(30) /\left(\mathrm{kcal}^{*} \mathrm{~mol}^{-1}\right)$ values, dipole moments $(\mu)$, dielectric constants $(\varepsilon)$, and polarity indices for xylene, THF, and chloroform.

\begin{tabular}{|c|c|c|c|}
\hline & Xylene & THF & $\mathrm{CHCl}_{3}$ \\
\hline $\mathrm{E}_{\mathrm{T}}(30) /\left(\mathrm{kcal}^{*} \mathrm{~mol}^{-1}\right)$ & 33.1 & 37.4 & 39.1 \\
\hline$\mu$ (debyes) & 0 & 1.63 & 1.08 \\
\hline$\varepsilon_{\mathrm{r}}$ & 2.2 & 7.5 & 4.5 \\
\hline Polarity index ${ }^{a}$ & $\sim 2.5$ & 4.0 & 4.1 \\
\hline
\end{tabular}



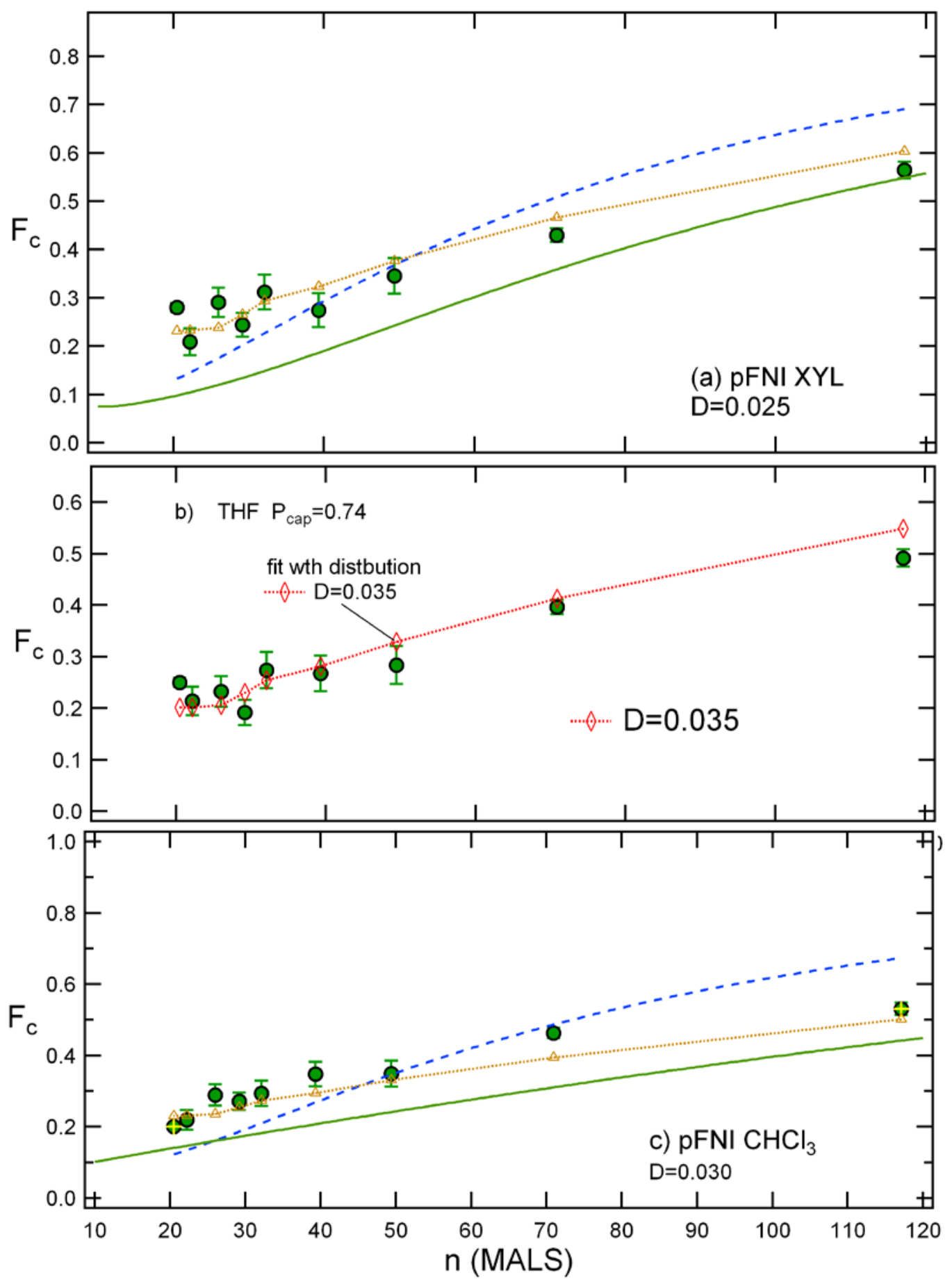

Figure S6. Fits of the intensity of chain fluorescence plotted as a fraction, $\mathrm{F}_{\mathrm{c}}$, of the fluorescence vs. the average length in repeat units for the nine length fractions of pFNI. The three panels show data in three solvents. The fits to a model of homogeneous diffusion (eq 5) include averaging over the distribution of lengths for each polymer fraction as in Figure $7 \mathrm{~b}$ ). 


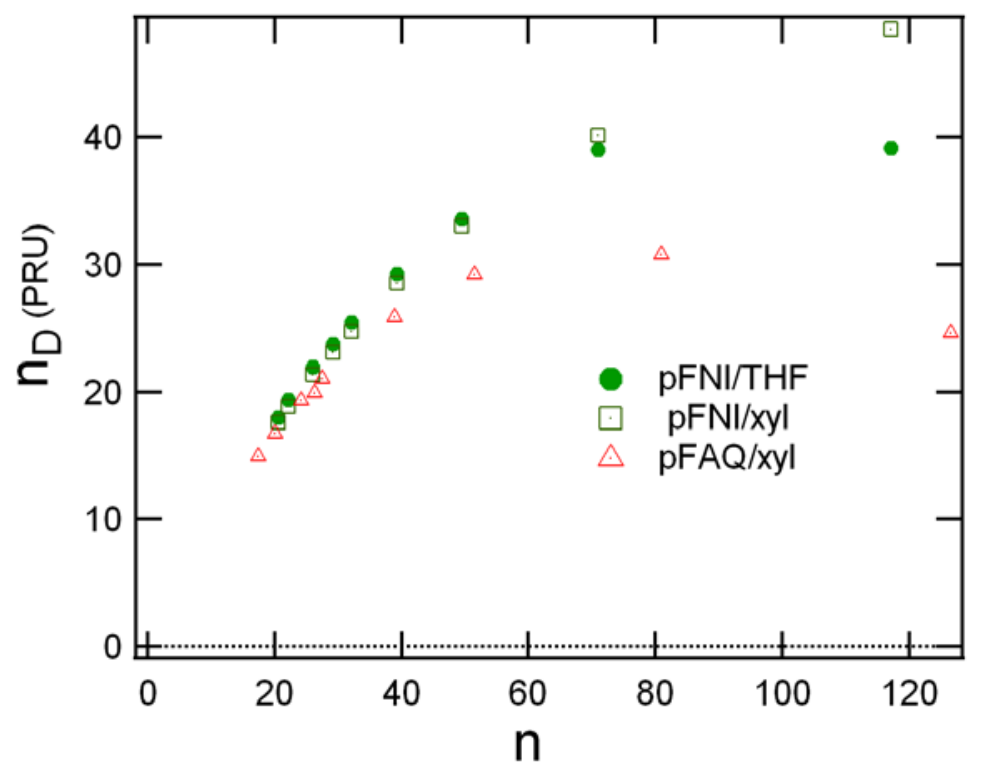

Figure S7. Diffusion lengths in repeat units, $\mathrm{n}_{\mathrm{D}}$, deduced from fits using the defect model (eq 8) plotted vs. the lengths of the chains.

(1) Klaerner, G.; Miller, R. D., Polyfluorene Derivatives: Effective Conjugation Lengths from Well-Defined Oligomers, Macromolecules 1998, 31, 2007-2009.

(2) Han, Y.; Fei, Z.; Sun, M.; Bo, Z.; Liang, W.-Z., Unusual Aggregation of Nanosized Six-Arm Star Oligofluorenes, Macromol. Rapid Commun. 2007, 28, 1017-1023.

(3) Koizumi, Y.; Seki, S.; Tsukuda, S.; Sakamoto, S.; Tagawa, S., Self-Condensed

Nanoparticles of Oligofluorenes with Water-Soluble Side Chains, J. Am. Chem. Soc. 2006, 128, 9036-9037.

(4) Penfield, K. W.; Miller, J. R.; Paddon-Row, M. N.; Cotsaris, E.; Oliver, A. M.; Hush, N. S., Optical and Thermal Electron Transfer in Rigid Difunctional Molecules of Fixed Distance and Orientation, J. Am. Chem. Soc. 1987, 109, 5061-5. 